\title{
Are Owls and Larks Different When it Comes to Aggression? Genetics, Neurobiology, and Behavior
}

\author{
Scott H. Deibel ${ }^{1 *}$, Robert J. McDonald ${ }^{2}$ and Nathan J. Kolla ${ }^{3,4,5 *}$ \\ ${ }^{1}$ Department of Psychology, Memorial University of Newfoundland, St. John's, NL, Canada, ${ }^{2}$ Department of Neuroscience, \\ University of Lethbridge, Lethbridge, AL, Canada, ${ }^{3}$ Waypoint Centre for Mental Health Care, Penetanguishene, ON, Canada, \\ ${ }^{4}$ Centre for Addiction and Mental Health, Toronto, ON, Canada, ${ }^{5}$ Department of Psychiatry, University of Toronto, Toronto, \\ ON, Canada
}

OPEN ACCESS

Edited by: Giuseppe Curcio,

University of L'Aquila, Italy

Reviewed by:

Sara Palumbo,

University of Pisa, Italy

Shimon Amir,

Concordia University, Canada

${ }^{*}$ Correspondence:

Scott H. Deibel

deibel@alumni.uleth.ca

Nathan J. Kolla

nkolla@waypointcentre.ca

Specialty section:

This article was submitted to Individual and Social Behaviors, a section of the journal Frontiers in

Behavioral Neuroscience

Received: 06 November 2019

Accepted: 25 February 2020

Published: 17 March 2020

Citation:

Deibel SH, McDonald RJ and Kolla NJ (2020) Are Owls and Larks

Different When it Comes to

Aggression? Genetics, Neurobiology, and Behavior:

Front. Behav. Neurosci. 14:39. doi: 10.3389/fnbeh.2020.00039
This review focuses on the contribution of circadian rhythms to aggression with a multifaceted approach incorporating genetics, neural networks, and behavior. We explore the hypothesis that chronic circadian misalignment is contributing to increased aggression. Genes involved in both circadian rhythms and aggression are discussed as a possible mechanism for increased aggression that might be elicited by circadian misalignment. We then discuss the neural networks underlying aggression and how dysregulation in the interaction of these networks evoked by circadian rhythm misalignment could contribute to aggression. The last section of this review will present recent human correlational data demonstrating the association between chronotype and/or circadian misalignment with aggression. With circadian rhythms and aggression being a burgeoning area of study, we hope that this review initiates more interest in this promising and topical area.

Keywords: circadian rhythms, aggression, circadian misalignment, chronotype, genetics, neurobiology, behavior

\section{INTRODUCTION}

In chronobiology, chronotype refers to one's sleep-wake timing (Roenneberg, 2012). Genetics, age, gender, and environmental stimuli contribute to the expression of chronotype (Barclay et al., 2013; Foster et al., 2013; Wicht et al., 2014). Recent evidence suggests that the colloquial statement "the early bird gets the worm" holds some weight as evening preference is associated with a higher incidence of disease (Roenneberg and Merrow, 2016). Human aggression has a sizable impact on society with exorbitant resources allocated to its reduction or aftermath. Recent research suggests that the use of aggression is higher in evening types, with several studies suggesting that traits involved in pre-meditated aggression are also associated with a late chronotype (Jonason et al., 2013; Schlarb et al., 2014; Rahafar et al., 2017). The deleterious effects associated with an evening preference could be the simple result of experiencing chronic, but mild circadian rhythm disruption.

This work is a scoping/narrative review that will discuss the relationship between circadian rhythms and aggression, with a broad focus that encompasses genetics, neural circuitry, and human behavior. The following keywords were entered in various combinations into Google Scholar in December 2018 to inform our review: chronotype, eveningness, psychopathy, antisocial personality disorder (ASPD), aggression, reactive aggression, proactive aggression, circadian rhythms, neurobiology, genetics, polymorphisms, rodents, and humans. 
The tenet of this article is that circadian rhythm dysfunction contributes to aggression. To guide this supposition, we draw from the wealth of genetic association studies, animal models of circadian rhythms and aggression, and human correlational data. The first section of this article will discuss circadian rhythm misalignment and aggression. The second section of this article will focus on several genes implicated in circadian rhythms that could contribute to aggressive behavior. The third section of the article will outline how the neural networks underlying forms of aggression are similar to those involved in learning and memory and how the dysfunction present in both aggression and circadian rhythm disruption involves changes in the interactions of these networks. Finally, we will discuss recent human correlational data, which demonstrates that chronotype and/or circadian misalignment are associated with aggression.

\section{SECTION 1: CIRCADIAN MISALIGNMENT AND AGGRESSION}

\section{Circadian Rhythm Misalignment}

To better take advantage of the environment, behavior and physiological processes need to occur at the appropriate time. Circadian rhythms can be thought of as our internal timekeepers that regulate oscillating behavior and physiology that takes approximately $24 \mathrm{~h}$ to complete one revolution. Body temperature, hormone secretion, metabolism, and the timing of sleep, activity, and meals are other processes that are modulated by circadian rhythms (Barnard and Nolan, 2008; Zelinski et al., 2014a; Roenneberg and Merrow, 2016). In order to predict events, circadian rhythms need to be synchronized with the environment. Light is the strongest entraining cue (zeitgeber), but food, exercise, social interaction, drugs, temperature, and learning can entrain circadian rhythms in certain circumstances (Merrow et al., 2005; Ralph et al., 2013; Krishnan and Lyons, 2015).

If the goal of circadian rhythms is to predict environmental events, what happens when there is a discrepancy between internal and external time? As eloquently put by Roenneberg and Merrow (Roenneberg and Merrow, 2016): "Without entrainment, the system loses its main advantage-faithfully predicting the regular changes of its environment (pg. R432)." They further highlight the gravity of this situation by positing that inaccurate circadian predictions are perhaps more detrimental than if there were no circadian predictions at all (Roenneberg and Merrow, 2016). It can be thought of as a sub-optimal form of entrainment (Roenneberg and Merrow, 2016). Circadian misalignment, in the simplest sense, occurs when we are active when we should be sleeping. It can present in its mildest form as waking up earlier with an alarm clock or more seriously as working throughout the night. Readers are encouraged to consult the excellent review by Baron and Reid (2015) that outlines circadian misalignment and its impact on health and disease.

Circadian rhythm misalignment has many deleterious effects on human health (Barnard and Nolan, 2008; Escobar et al., 2011; Zelinski et al., 2014a). Major problems that affect virtually all aspects of physiology arise when circadian rhythms are unsynchronized from the environment (Kuhn, 2001; Zelinski et al., 2014a). Chronic circadian rhythm misalignment has been associated with cognitive impairments, heart disease, metabolic syndrome, shortened lifespan, and cancer (Haus and Smolensky, 2006; Zelinski et al., 2014a; Banks et al., 2016). Artificial light at night is purported to be the major mechanism for the harmful effects of circadian misalignment on the brain and the body (Navara and Nelson, 2007; Bedrosian and Nelson, 2017).

While approximately $20 \%$ of the workforce in industrialized countries engage in shift work (Baron and Reid, 2015), most people are likely experiencing a milder yet chronic state of circadian rhythm disruption. It is thought that in some cases circadian misalignment in society is a result of one's preferred timing of their sleep-wake rhythm (Baron and Reid, 2015). This Interindividual variation in the phase of entrainment is referred to as chronotype (Horne and Östberg, 1976; Roenneberg et al., 2003, 2004; Levandovski et al., 2013; Roenneberg and Merrow, 2016). Although chronotype exists on a continuum, in the extremes of the distribution, there are people who wake and go to sleep early (larks; morning types) and others who do so later (owls; evening types; Roenneberg, 2012; Levandovski et al., 2013; Roenneberg and Merrow, 2016). There are also intermediate (neither morning or evening type), which creates three chronotype classifications (Roenneberg et al., 2004; Adan et al., 2012). Neither or intermediate type is the most common in the population $(60 \%)$, with the remaining being either morning (20\%) or evening types (20\%; Adan et al., 2012).

Misalignment could be a result of a mismatch between a person's natural sleeping preference and the schedule dictated by his or her work and social habits (Baron and Reid, 2015). Some studies have indeed found that in late chronotypes, there is circadian misalignment among sleep and markers of phase (Kerkhof and Lancel, 1991; Duffy et al., 1999; Mongrain et al., 2006). While sleep duration does not always correlate with chronotype (Horne and Östberg, 1976; Robilliard et al., 2002; Randler and Vollmer, 2013), as discussed below, sleep duration can vary during the week and weekend in a chronotype dependent manner (Wittmann et al., 2006; Adan et al., 2012; Randler et al., 2017). This misalignment puts individuals in a continuous state of catch-up, or chronic circadian misalignment, and is referred to as social jetlag (Wittmann et al., 2006). While an evening chronotype does not always incur social jetlag, it is more common in evening chronotypes (Wittmann et al., 2006; Baron and Reid, 2015; Roenneberg and Merrow, 2016). In other words, social jetlag can be thought of as a discrepancy between an individual's work schedule and his or her endogenous clock (Baron and Reid, 2015). Strikingly, $87 \%$ of day workers $(65,000$ people located in central Europe) experienced social jetlag (Roenneberg et al., 2012). Social jetlag is a less severe form of shift work, but nonetheless a form of chronic circadian misalignment (Wittmann et al., 2006; Roenneberg and Merrow, 2016).

\section{Aggressive Behavior}

Aggression is a heterogeneous group of behaviors, but it is broadly defined as any behavior that threatens to, or does harm/injure others (Berkowitz, 1993; Baron and Richardson, 
2004). It is an adaptive behavior if displayed in the appropriate context; however, if exaggerated and/or it often occurs in inappropriate contexts, it is considered maladaptive (Bedrosian and Nelson, 2018). Aggressive behavior is found in virtually all species, with some species being more aggressive than others. Aggression has a major impact on society; in addition to concerns of safety, significant resources are allocated to curtail or ameliorate the aftermaths of aggression (Temcheff et al., 2011; Waltes et al., 2016).

From a psychiatric perspective, there are several disorders in The Diagnostic and Statistical Manual of Mental Disorders Version 5 (American Psychiatric Association, 2013), that strongly feature aggression, such as conduct disorder, oppositional defiant disorder, intermittent explosive disorder, ASPD and borderline personality disorder. However, as highlighted by van Donkelaar (2018), categorical diagnoses and featured comorbidities, such as aggression, are likely extremes in a normally distributed continuum of the behavior in question rather than binary constructs.

ASPD, which we discuss throughout this review, is characterized by impulsivity and high levels of aggression, with a prevalence of approximately $7 \%$ in the community and $50 \%$ in the penal system (Swanson et al., 1994; Fazel and Danesh, 2002; Coid et al., 2006). ASPD presents initially as conduct disorder during youth. Hence, adults with ASPD are likely to have had other externalizing conditions as children or adolescents (Reef et al., 2011; Waltes et al., 2016).

Psychopathy is related to ASPD but differs in several key ways. In addition to antisocial behavior, psychopathy includes impaired emotional responses such as decreased empathy, remorse and guilt (Hare, 1996). Individuals with psychopathy are ego-driven and do not abide by social norms (Hare, 1996; Blair, 2003). Defiance of social norms is thought to be mediated by impaired emotional recognition in others, the inability to recognize that behavior has aversive consequences, and the failure to stop behaviors that have elicited negative consequences in the past (Blair, 2003). In terms of prevalence, it is estimated that $1 \%$ of the general, and $15-25 \%$ of the penal population endorse psychopathy (Hare, 1996). One-third of those with ASPD meet the criteria for psychopathy (Hart and Hare, 1996; Blair, 2003).

While debated, it is generally assumed that humans are one of the more aggressive species (Waltes et al., 2016; Wrangham, 2018). The contention regarding this statement might be due to the fact that aggression is a multi-faceted construct (Wrangham, 2018). There are many different terms and classification systems for the different kinds of aggression, but they can generally be differentiated into two broad categories: proactive (pre-meditated) and reactive (impulsive; Waltes et al., 2016; Wrangham, 2018). One's motivation for engaging in aggression is the key distinguisher between these two types of aggression (Raine et al., 2006). Proactive aggression is planned aggression that is executed when one judges that he or she is likely to achieve an extrinsic or intrinsic goal (Wrangham, 2018). Bullying, stalking, and premeditated homicide are an example of proactive aggression (Wrangham, 2018). Proactive aggressors are more likely to be recidivists and endorse psychopathy
(Kockler et al., 2006; Stanford et al., 2008; Swogger et al., 2015; Wrangham, 2018). In comparison, reactive aggression is executed to remove an aversive stimulus and is often driven by frustration or eruption of anger (Wrangham, 2018). Crimes of passion and bar fights prompted by intoxication are examples of reactive aggression (Wrangham, 2018). Along these lines, emotional arousal further distinguishes the two types of aggression, with proactive aggression involving little emotional arousal and reactive aggression involving more (Raine et al., 2006; Wrangham, 2018). Anger is always associated with reactive aggression (Wrangham, 2018). In addition to behavior, these different types of aggression are thought to have disparate underlying neurobiologies and neurocognition (van Donkelaar et al., 2020). These constructs also have convergent properties as they are very highly intercorrelated and are often both present in populations with pathologies that feature aggression, such as antisocial and borderline personality disorders (Gardner et al., 2012; Lobbestael et al., 2013; Rosell and Siever, 2015).

Aggressive behavior can be distinguished by the motivating factors and goals for its execution. Like chronotype, aggressive behavior is thought to exist on a continuum and is thought to be normally distributed in the population (Roenneberg, 2012; Levandovski et al., 2013; Walters and Ruscio, 2013; Roenneberg and Merrow, 2016; Waltes et al., 2016; van Donkelaar, 2018). It is important to elucidate the etiology of aggression, with the hope of reducing its prevalence. Circadian misalignment is one hypothetical mechanism for aggressive behavior. Although this hypothesis is largely untested, the next discussion will provide tangential evidence suggesting that circadian misalignment contributes to the manifestation of aggressive behavior.

\section{Circadian Misalignment Is a Possible Mechanism for Aggression}

While most studies that have reported an effect of chronotype in relation to health and disease name circadian misalignment as a likely mechanism, these findings are rarely confirmed (Baron and Reid, 2015). To the best of our knowledge, no study has investigated whether aggression is accompanied by objective measures of circadian rhythm misalignment. In theory, the notion that circadian misalignment elicits increased aggression would rely on diurnal differences in aggression. Chronotype differences in aggression have been proposed as evidence that circadian fluctuations influence aggression (Hood and Amir, 2018). The presence of increased verbal and physical aggression in the afternoon in Alzheimer's disease patients has also been suggested as one explanation for diurnal differences in aggression (Coogan et al., 2013; Hood and Amir, 2018). However, until now, there has never been a demonstration that aggression is influenced by an endogenously-generated circadian rhythm (Hood and Amir, 2018). For the first time, Todd et al. (2018) demonstrated in mice that there is a true circadian rhythm in territorial aggression that persists under constant conditions (without zeitgebers). The resident-intruder model of reactive aggression was used to measure aggression. In this model, a rodent is singly housed for a month, which produces territorial aggression when a conspecific is introduced to their home cage. The authors concluded that either direct suprachiasmatic 
nucleus (master pacemaker in the brain; SCN) outputs or indirect ones via the subparaventricular zone influence the ventromedial hypothalamus's modulation of aggression in a circadian manner (Todd et al., 2018). If aggression is under circadian control, it is, therefore, possible that circadian misalignment could increase the likelihood of aggressive behavior.

Several factors suggest that circadian misalignment is a possible mechanism underlying the effects of a late chronotype on aggression. First, as mentioned above, in the few studies that have assessed this line of research, a late chronotype is associated with circadian misalignment of rhythms such as melatonin release and body temperature during sleep (Kerkhof and Lancel, 1991; Duffy et al., 1999; Mongrain et al., 2006).

Second, there is a large corpus of literature linking self-reported sleep disruption or poor sleep quality with increased aggression (Kamphuis et al., 2012; Krizan and Herlache, 2016). For example, sleep disruption is a predictor of aggression, as measured by the observer-scale: The Social Dysfunction and Aggression Scale (SDAS; Wistedt et al., 1990), in prisoners with or without psychiatric histories (Vogler et al., 2014; Meijers et al., 2015). Reduced sleep duration is also associated with increased verbal aggression and anger (Randler and Vollmer, 2013). Sleep disturbances also relate to increased psychopathic and Machiavellianism traits as measured by the Short Dark Triad questionnaire (Sabouri et al., 2016; Akram et al., 2018). Sleep is partially modulated by circadian rhythms, with the timing of sleep (sleep-wake cycle; chronotype) controlled by the SCN. Disrupted sleep and/or daytime tiredness may be one of the most significant consequences of circadian misalignment (Baron and Reid, 2015). Not surprisingly, shift workers experiencing circadian misalignment also report impacted sleep schedules (Reinberg and Ashkenazi, 2008; Saksvik-Lehouillier et al., 2015). Since late chronotype is associated with poor sleep quality, shorter sleep duration, and daytime tiredness (Giannotti et al., 2002; Robilliard et al., 2002; Taillard et al., 2003, 2004; Juda et al., 2013; Horne et al., 2019), it is possible that sleep disruption could underscore the influence of chronotype-mediated circadian misalignment on aggression.

Third, disruption of circadian rhythms in Alzheimer's disease might also speak to the relationship between circadian misalignment and aggression. Circadian misalignment and sleep disruption are hallmarks of Alzheimer's disease (Coogan et al., 2013; Deibel et al., 2015; Deibel and McDonald, 2017). Sundowning, which involves increased activity and agitation/aggression in the late afternoon in dementia patients (Coogan et al., 2013), could be the result of circadian misalignment since circadian dysfunction is associated with more observable verbal and physical aggression in Alzheimer's disease patients (Etcher et al., 2012). While there are likely several pathologies leading to agitation/aggression in Alzheimer's disease, circadian rhythm misalignment seems a likely contributor.

There are a variety of factors which suggest that circadian misalignment could be a mechanism for the association between eveningness and increased aggression. However, to our knowledge, quantitative measures of circadian misalignment, such as melatonin rhythmicity have not been assessed in relation to aggression. Genetics provides another avenue to explore the link between circadian rhythms and aggression. Circadian misalignment might elicit aggression, but the mechanisms for this effect remain to be seen. Altered gene expression elicited by genetic polymorphisms and/or environmental circadian rhythm disruption could lead to increased aggressive behavior. The next section will explore recent research highlighting the putative genetic contributions to circadian rhythm generation and aggression.

\section{SECTION 2: GENES}

\section{Genes Involved in Circadian Rhythm Generation and Aggression}

Aggression and chronotype are heritable traits, with genetics explaining approximately $50 \%$ of the variance in twin studies (Koskenvuo et al., 2007; Burt, 2009; Barclay et al., 2010, 2013; Tuvblad and Baker, 2011). Non-shared environmental experiences also account for a large portion of the variance (Koskenvuo et al., 2007; Barclay et al., 2010, 2013; Veroude et al., 2016; Waltes et al., 2016).

There are a group of genes referred to as "core clock genes," found in virtually all cell types, that generate circadian rhythmicity via a cell-autonomous, transcriptional-translational autoregulatory feedback loop (Reppert and Weaver, 2001; Okamura, 2004; Takahashi, 2017). The activators consist of the transcription factors Circadian Locomotor Output Cycles Kaput CLOCK [and its paralog Neuronal PAS domain protein 2 (NPAS2)] and Aryl hydrocarbon receptor nuclear translocator-like protein [BMAL1 (ARNTL); Reppert and Weaver, 2001; Okamura, 2004; Takahashi, 2017]. They form heterodimers and activate the transcription of genes encoding the following repressor proteins: PERIOD (PER1, PER2, PER3) and cryptochrome (CRY1, CRY2; Okamura, 2004; Takahashi, 2017). PER and CRY proteins then dimerize and transfer to the nucleus to inhibit the transcription of Clock and Bmall (Reppert and Weaver, 2001; Okamura, 2004; Takahashi, 2017). Another regulatory loop influences the core loop with the nuclear receptor and transcriptional repressor REV-ERB, attenuating Bmal1 transcription in a rhythmic fashion (Reppert and Weaver, 2001; Okamura, 2004; Takahashi, 2017). This cycle takes approximately $24 \mathrm{~h}$ (Takahashi, 2017).

Many studies of aggression have assessed genes that were selected for their perceived relevance in aggressive behavior. However, effect sizes tend to be small and results do not always replicate across studies. With the advent of GWAS, progress will be made in identifying genetic loci of aggressive behavior. Most candidate gene association studies of aggression have studied serotonergic (5-HT), dopaminergic (DA), and hormonal genes (Veroude et al., 2016; Waltes et al., 2016; Bedrosian and Nelson, 2018). Altered levels of 5-HT and DA have been implicated in aggressive behavior. In animals and humans, lower brain, blood, and cerebrospinal fluid levels of the 5-HT metabolite 5-hydroxy indoleacetic acid (5-HIAA) has been associated with increased aggression (Ramboz et al., 1995; 
Tuinier et al., 1995; Higley et al., 1996; Coccaro et al., 1998; Angoa-Pérez et al., 2012; Provençal et al., 2015; Bedrosian and Nelson, 2018). In humans, decreased DA can be associated with increased impulsive/reactive aggression (Schlüter et al., 2013; Rosell and Siever, 2015; Bedrosian and Nelson, 2018), however, the reinforcing or hedonic aspect of aggression is associated with increased DA in a region of the striatum involved in reward processing [nucleus accumbens (NA; Ferrari et al., 2003; Buckholtz et al., 2010; Bedrosian and Nelson, 2018)].

\section{Genetic Polymorphisms in Circadian Genes and Aggression}

Genetically selecting for aggression results in a specific circadian phenotype (Benus et al., 1988). Notably, there was a longer free-running period and much longer re-entrainment to a zeitgeber change when animals were selected for aggression (Benus et al., 1988). However, it is unknown whether aggression led to altered circadian rhythms or whether an altered circadian phenotype contributed to heightened aggression. Regardless, it is likely that these differences were the result of altered clock gene expression in the SCN. The finding that Clock expression in the SCN and circadian expression of molecules involved in the stress response were altered in aggressive and impulsive rats supports this notion (Kerman et al., 2012). Data from transgenic mice with mutations affecting clock genes suggest that circadian dysfunction can elicit aggression (Hood and Amir, 2018). For example, knocking out the clock genes reverb alpha (Chung et al., 2014) and clock (Roybal et al., 2007; Coque et al., 2011) increases resident-intruder aggression, and hyperactivity/impulsivity, respectively.

Polymorphisms in circadian genes have been associated with both chronotype and aggression, especially in 5-HT and DA genes, where dysregulation is thought to mediate aggression (Tuinier et al., 1995; Higley et al., 1996; Coccaro et al., 1998; Provençal et al., 2015; da Cunha-Bang et al., 2016). For example, recent GWASs have identified loci near clock genes and those involved in the serotonergic system that highly influence morning or evening preferences (Hu et al., 2016; Jones et al., 2016; Hood and Amir, 2018). However, genetic association studies with aggression and core clock gene polymorphisms have not yet been conducted. Nonetheless, there are several genes involved or influenced by circadian rhythms that could theoretically elicit aggression when dysregulated.

Recent data have suggested that Sirtuin 1 (Sirt1), a gene involved in circadian rhythm generation, could also be relevant to the elicitation of aggression. Sirt1 is a histone and protein deacetylase enzyme whose main function is to repress CLOCK(positive activator core clock gene) mediated transcription by deacetylating promoter regions of core clock genes: BMAL1 and PER2 (Asher et al., 2008; Nakahata et al., 2008, 2009). Sirt1 knockout mice manifest disrupted circadian rhythms (elongated free-running period), likely due to decreased CLOCK and BMAL1 proteins, and reduced Bmal1 and Per2 RNA in the SCN (Chang and Guarente, 2013). In humans, the minor Sirt1 rs1467568 allele (AG or AA) has been associated with eveningness (Katzenberg et al., 1998; Kripke et al., 2008; Garaulet et al., 2012). This variant was also associated with eveningness when concomitant with the minor allele of Clock 1131T>C (TC or CC) single nucleotide polymorphism (SNP; Garaulet et al., 2012). In a Chinese population of male juveniles, Sirt1 polymorphisms were associated with a predisposition for ASPD (Chang et al., 2017). Chang et al. (2017) suggest that altered SIRT1 expression disrupts circadian rhythms and that disruption contributes to the pathogenesis of ASPD. The finding that Sirt1 polymorphisms have also been associated with a late chronotype type bolsters the argument (Garaulet et al., 2012; Chang et al., 2017).

It is possible that clock gene polymorphisms modulate genes that regulate aggression (Hood and Amir, 2018). Monoamine oxidase-A (MAO-A) catabolizes 5HT, norepinephrine (NE), and $\mathrm{DA}$ and is perhaps the most studied and robust candidate gene for aggressive behavior (Veroude et al., 2016; Waltes et al., 2016; Kolla and Vinette, 2017). Mao- $a$ possesses a variable number tandem repeat (VNTR) that results in less (Maoa- $L$ ) or more efficient transcription (Maoa-H). However, counterintuitively, no correlation has been found between the amount of brain MAO-A and the VNTR genotypes (Fowler et al., 2007; AliaKlein et al., 2008; Shumay et al., 2012). While most studies find that Maoa- $L$ is associated with aggression, others have implicated Maoa-H (Kolla et al., 2014; Tiihonen et al., 2015; Veroude et al., 2016; Waltes et al., 2016; Kolla and Vinette, 2017). This effect likely depends on a variety of factors such as age, sex, concomitant conditions, and type of aggression.

Since MAO-A oscillates in brain areas, such as the ventral tegmental area (VTA) and the ventral striatum (NA), it is not surprising that clock genes are involved in its regulation (Hampp et al., 2008). It has been proposed that clock gene polymorphisms might modulate the regulatory role of MAO-A in aggression (Hood and Amir, 2018). BMAL1 and PER2 increase transcription of MAO-A, with PER2 playing an activating role (Hampp et al., 2008). In PER2 knockout mice, MAO-A expression is attenuated and fails to oscillate (Hampp et al., 2008). Due to reduced MAO-A, striatal DA is increased in these animals. SIRT1 is also involved in the activation of MAO-A via the deacetylation of the transcription factor Nescient HelixLoop-Helix 2 (NHLH2; Libert et al., 2011). In contrast to PER2 knockout mice, SIRT1 knockout mice have increased 5HT, and not DA (Hampp et al., 2008; Libert et al., 2011). Correspondingly, they also show fewer behaviors consistent with anxiety and depression (Libert et al., 2011).

Besides its effect on DA via regulation of MAO-A, SIRT1 is also directly involved in DA synthesis. Tyrosine hydroxylase $(\mathrm{TH})$ is the rate-limiting enzyme in DA synthesis. The VTA is the primary site of DA synthesis, and $\mathrm{TH}$ is expressed diurnally in the VTA with peak expression during the night in mice (Logan et al., 2018). While CREB is responsible for upregulating $\mathrm{TH}$ expression during the evening; interestingly, CLOCK inhibits $\mathrm{TH}$ expression during the nadir (daytime; Logan et al., 2018). The inhibiting action of CLOCK depends on SIRT1 and its cofactor nicotinamide adenine dinucleotide (NAD+; Logan et al., 2018). Clock knockout mice have elevated TH and increased levels of DA in the VTA. The same Clock knockout mice also exhibit increased hyperactivity and impulsivity (Roybal et al., 2007; Coque et al., 2011). Although association studies with 
Clock polymorphisms and aggression have not been performed, clock polymorphisms have been linked to other illnesses that can involve aggression, such as attention deficit hyperactivity disorder (ADHD). Disturbed sleep and symptoms typically associated with circadian misalignment, such as irritability, mild depression, daytime tiredness, and impaired cognition can also occur in ADHD (Katz et al., 2001; Baird et al., 2012; Mogavero et al., 2018).

The SIRT1 data detailed above suggest that SIRT1 polymorphisms contribute to both chronotype and aggression. SIRT1 likely influences aggression via its regulatory role of MAOA and subsequently DA and 5-HT expression. SIRT1 also affects DA directly via its effect on CLOCK, which although untested, opens up the possibility that Clock polymorphisms might contribute to aggression.

SIRT1 is involved in the regulation of another gene, brainderived neurotrophic factor (BDNF), that has been implicated in mediating the effects of adverse childhood experiences on aggression. BDNF is a rhythmically expressed gene in the SCN and other brain regions, such as the hippocampus, that is implicated in cellular plasticity, neuronal survival, and morphogenesis (Liang et al., 1998; Earnest et al., 1999; Schaaf et al., 2000; Katoh-Semba et al., 2008; Rudenko and Tsai, 2014). BDNF is part of the mitogen-activated protein kinase signaling cascade, which underlies many biological processes, including regulation of circadian rhythms, learning, and memory (EckelMahan and Storm, 2009; Gao et al., 2010; Rudenko and Tsai, 2014; Peixoto et al., 2015). BDNF is thought to be involved in the SCN's response to photic input (Michel et al., 2006; Naert et al., 2006), with BDNF knockout mice showing decreased response to light pulses (Liang et al., 2000). BDNF may also modulate aggressive behavior, with exogenous BDNF eliciting proactive aggression in a highly aggressive mutant mouse strain (AKR; Naumenko et al., 2014).

Several studies suggest that the BDNF met-met polymorphism moderates the effect of adverse childhood experiences on aggression (Wagner et al., 2010; Kretschmer et al., 2012). Many of the genotypes implicated in aggression or impulsivity are often mediated by adverse environmental experiences (Caspi et al., 2002; Kendler et al., 2011; Kolla et al., 2017a). In Borderline Personality subjects, a condition that is marked by frequent anger outbursts and impulsive aggression, Wagner et al. (2010) found that those who carried the Met/Met allele of the BDNF Val ${ }^{66}$ Met polymorphism had higher impulsive aggression scores on the Buss-Durkey-Hostility inventory (Buss and Durkee, 1957) if they had experienced childhood sexual abuse, or exposure to aggressive peers during the late stages of childhood (Wagner et al., 2010; Kretschmer et al., 2012).

SIRT1 acts as a positive regulator of BDNF by deacetylating methyl CpG binding protein 2 or by inhibiting the microRNA 134 (Gao et al., 2010). Hippocampal SIRT1 expression is affected by environmental manipulations that affect circadian rhythmicity, such as diet, sleep deprivation, shifts or inversions of the light-dark cycle, and genetic manipulation of clock genes (Chang et al., 2009; Heyward et al., 2012; Rawashdeh et al., 2014; Fang et al., 2017). BDNF is also affected by environmental manipulations that affect circadian rhythms, such as phase shifts of the light-dark cycle (Sei et al., 2003; Katoh-Semba et al., 2008). It is possible that changes in SIRT1 brain levels elicited by SIRT1 polymorphisms or environmental influences impact the manifestation of aggression via regulation of BDNF.

In addition to SIRT1, polymorphisms in arginine vasopressin may also influence circadian rhythms and aggression. Arginine vasopressin is a neuropeptide that modulates complex social behaviors; in the periphery, it acts as a hormone to regulate physiological processes, such as osmoregulation (Ebstein et al., 2009; Song and Albers, 2018). AVP and specifically the AVPR1a receptor (most common AVP receptor in the brain) are implicated in aggressive behavior (Ferris and Potegal, 1988; Ferris et al., 1997; Caldwell and Albers, 2004). Injecting AVP into the anterior hypothalamus can elicit aggression in hamsters, and this effect appears to be dependent on AVPR1a receptors since its antagonist reduces aggression when injected into the same area (Ferris and Potegal, 1988; Ferris et al., 1997; Caldwell and Albers, 2004). In humans, SNPs in Avprla have been associated with non-clinical childhood aggression that is assessed by parents (Pappa et al., 2016). This finding was unexpected as many candidate genes implicated in aggressive behavior were also tested: dopaminergic, serotonergic, stress, and adrenergic genes (Pappa et al., 2016).

The role of AVP in both aggression and circadian rhythms has interesting implications for how circadian rhythms might contribute to aggression. Although to our knowledge, it is unknown whether potential Avprla polymorphisms contribute to chronotype, animal data demonstrated that an increased AVP tone is associated with aggression, delayed circadian rhythms, and reduced circadian entrainability (Ferris et al., 1997; Caldwell and Albers, 2004; Yamaguchi et al., 2013). Epigenetics is a likely mechanism for an upregulated AVP tone. The Avprla gene promotor was less methylated in aggressive children, which the authors suggested was indicative of increased activity (Provençal et al., 2014). So, if AVP tone is elevated due to genetic polymorphisms or environmental factors, entrainment should be more difficult, which might create misalignment and heightened aggression.

In summary, there are several examples of how genetic polymorphisms of genes influenced by circadian rhythms could have distal effects on aggressive behavior (Figure 1). The genotypes discussed above may be more susceptible to circadian rhythm misalignment, and these changes could contribute to the symptomology of aggression and its associated disorders. We have also highlighted that this same mechanism may be driven by environmental influences rather than genotype. It is likely that this scenario would apply to most mechanisms hypothesized to modulate aggressive behavior. In summary, we contend that changes in gene expression that are elicited via genotype or environmental factors act in parallel or synergistically to influence aggression. Yet, how do changes in gene expression affect the functioning and interaction of brain circuits that modulate aggressive behavior? The next section will tackle this question. 


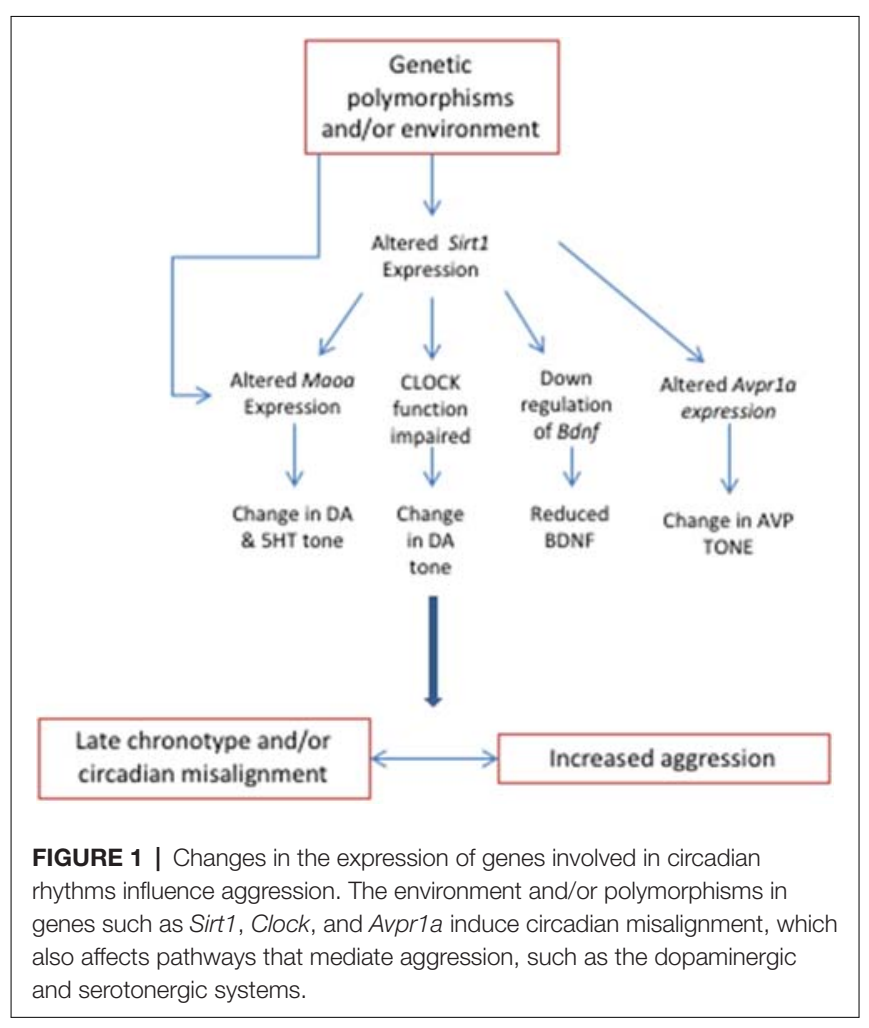

\section{SECTION 3: BRAIN CIRCUITS INVOLVED IN AGGRESSION}

While altered gene expression contributes to aggressive behavior, changes in behavior will not occur unless there are downstream changes in the structure/function of the brain regions/circuits involved. As aggression is a complex behavior, many areas and circuits are involved, particularly areas that are involved in learning/memory, and emotional regulation. We will first briefly introduce the key brain regions that are involved in aggression. We will then provide a unique explanation for how aggressive behavior could be elicited by changes in the interactions of parallel learning and memory circuits. Finally, the ability of circadian rhythm disruption to perturb these brain regions, circuits and neuromodulators will also be discussed.

\section{Key Regions Involved}

A thorough review of the regions and neural circuitry involved in aggression is beyond the scope of the present review. Readers are encouraged to refer to additional review articles for discussions of this nature (Rosell and Siever, 2015; Blair, 2016; Ling and Raine, 2018). We will briefly discuss the involvement of some regions below in aggression to provide context for how circadian rhythm disruption might act on these regions to produce aggressive behavior.

The amygdala is involved in fear and emotion recognition. Flat affect; callous, unemotional traits and lack of empathy are associated with psychopathy; amygdalar dysfunction is likely involved (Ling and Raine, 2018). Impaired amygdalar functioning leads to aberrant or failure to form stimulus- response associations, which could precipitate inappropriate behavior because the negative outcomes are not anticipated (Gruber and McDonald, 2012; Ling and Raine, 2018). Reduced amygdala volume in both forensic and community populations is strongly associated with aggression (Matthies et al., 2012; Pardini et al., 2014; Rosell and Siever, 2015; Ling and Raine, 2018). Interestingly, in violent individuals, the Maoa VNTR genotype affects the amygdalar surface area (Kolla et al., 2017b). These data are some of the first to demonstrate that in violent individuals, genotype contributes to morphological differences in brain regions implicated in aggression.

The ventral medial prefrontal cortex (vmPFC) and its subregions-orbitofrontal cortex (OFC), and anterior cingulate cortex (ACC) - are thought to modulate the likelihood of an aggressive response. The OFC evaluates the motivational value and affective valence of stimuli, whereas the ACC is thought to be involved in determining the action or response (Rosell and Siever, 2015). Dysregulation in the vmPFC could affect decision making, with inappropriate social outcomes likely selected (Bechara et al., 1999; Ling and Raine, 2018). Interestingly, decision making in patients with vmPFC and/or OFC damage is very similar to that of individuals with psychopathy, which commonly features proactive aggression (Koenigs et al., 2007; Ling and Raine, 2018). Psychopathy has been associated with reduced PFC total volume and reduced PFC/OFC gray matter volume (de Oliveira-Souza et al., 2008; Ermer et al., 2012; Ling and Raine, 2018).

The striatum is thought to be involved in the impulsiveantisocial and the interpersonal-affective features of aggression (Ling and Raine, 2018). The ventral striatum, which has been implicated in primary reward representations and expected outcomes following Pavlovian associative learning processes, and the dorsomedial striatum, which has been linked to cognitive control of instrumental responses and goal-directed behaviors (Gruber and McDonald, 2012), are two striatal areas of interest. These brain regions have been shown to elicit abnormal responses in individuals with various aggressive phenotypes (Crockett et al., 2013). Accordingly, increased striatal volumes in both forensic and community populations are associated with psychopathy (Cope et al., 2012; Korponay et al., 2017). Our group has conducted functional connectivity studies involving the striatum in relation to MAOA. In impulsive and violent patients with ASPD and high levels of psychopathy, there was a positive correlation with MAOA brain expression and functional connectivity of the superior ventral striatum with the dorsomedial PFC (Kolla et al., 2016). These are some of the first data that suggest that brain levels of MAOA can influence functional connectivity between brain areas that are involved in the regulation of aggressive behavior.

In summary, brain regions involved in learning/memory and emotional regulation modulate aggressive behavior. Changes in the structure and/or functioning of these regions likely increase aggressive behavior. Rosell and Siever (2015) suggested that the changes in functional connectivity are not always due to structural changes but could be a result of aberrant neuromodulation. Our finding that corticostriatal functional 
connectivity correlated with amounts of MAOA and also Maoa VNTR genotype supports this notion (Kolla et al., 2016, 2018).

\section{Interactions Among Parallel Learning and Memory Circuits Might Contribute to Aggression}

It seems clear that individuals with aggressive phenotypes have alterations in various brain areas implicated in learning and memory and cognitive control functions. However, the implications of these neural changes on behavior might not be fully appreciated. Some, over the last few decades, have argued that mammalian learning and memory functions are organized into different neural circuits that operate in parallel. These complex networks are comprised of brain regions throughout the expanse of the brain including cortical, subcortical, and brainstem regions. There exists a significantly large body of evidence identifying six parallel neural circuits that seem to support different learning and memory functions, each with a central structure (amygdala, hippocampus, dorsolateral striatum, dorsomedial striatum, perirhinal cortex, and cerebellum). One interesting line of research has provided evidence that these parallel, functional networks provide coherent outputs via cooperative and/or competitive interactions. These dynamic interactions between these networks, in the average person, are seen as the key to normal brain functions and outputs like coherent thought processes, appropriate emotional reactions, good choices and actions, and even personality type (McDonald et al., 2004; Gruber and McDonald, 2012). We have used this theory to explain both normal and abnormal manifestations via a balance amongst these systems in the former and alterations of this balance between these systems through the influence of various factors including genetics, preand postnatal development, and experience. So, in essence, these parallel networks, the way they are organized and shaped, and the way they dynamically interact with one another, determine who we are and how we behave in particular situations. We refer to these different functional networks as memory-based behavioral systems because they have such a fundamental influence on behavior. For the expansion of these concepts, readers are encouraged to consult the following reviews: McDonald et al. (2004) and Gruber and McDonald (2012).

What does this theory of brain function tell us about aggression and individuals with aggressive phenotypes? It is possible that aggressive individuals with alterations in the size, function, or influence of brain regions associated with specific memory-based behavioral systems is two-fold. First, changes of one of these memory-based behavioral systems not only impairs the function of that system but it also can result in enhanced influence and control of other parallel systems not affected. For example, the memory-based behavioral systems centered on the amygdala are thought to be critical for tracking stimuli that predict the presence of biologically significant events (positive and negative) and does so via Pavlovian associative mechanisms (for review see, McDonald et al., 2017). This can result in difficulties in accurately predicting when negative events might occur. This uncertainty in stressful and fear-inducing situations could lead to aggressive outcomes. The loss of amygdalar influence can have another effect, a release of thought and behavior control from this important functional network and an enhancement of other circuits that may not provide the appropriate solution during the conflict. For example, the instrumental system centered on the dorsomedial striatum is under the influence of amygdalar representations as well as various prefrontal regions implicated in executive functions like inhibitory control. This system is more flexible and takes into account the context of the situation, previous experience (episodic memory), and the internal state of the individual to make choices about what response to make in a given situation (Gruber and McDonald, 2012). It is possible if the dorsomedial striatum is reduced in size and functional capacity that higher-order cognitive control will be diminished, resulting in a reduction of the ability to predict the consequences of certain instrumental responses in a particular situation (context, threat, etc.), leading to aggressive responses. Reduction in the influence of this memory-based behavioral circuit could also lead to the increased influence of the habit system. If these individuals have found aggressive behaviors to be reinforcing and/or rewarding, this could increase the habitual nature of these responses and would be released if the dorsomedial striatum was compromised. This could pose a distinct problem for individuals with aggressive phenotypes, because if instrumental responding is not under cognitive control, the habit system, a memory-based behavioral system centered on the dorsolateral striatum, could gain control of behavior and elicit inappropriate and aggressive responses that have been learned in these situations in the past and have been repeatedly reinforced.

Interactions between parallel learning and memory circuits have been posited to regulate both normal and abnormal behavior. Changes in these interactions between parallel learning and memory circuits provide an avenue for investigating how genetics and experiences can influence behavior. Imbalances in the interactions of some of these circuits likely contribute to the manifestation of aggressive behavior. Interestingly, circadian rhythm disruption affects behavior mediated by these same circuits. The next section will present behavioral and neurophysiological evidence that circadian rhythm disruption influences many of the mechanisms that underlie aggressive behavior.

\section{Circadian Rhythm Disruption}

The previous section demonstrates that brain morphology, functional connectivity, and changes in interactions of neural circuits contribute to aggressive behavior. Circadian rhythm misalignment affects many of the same brain areas and circuits thought to underlie aggressive behavior.

First, circadian misalignment can inflict structural changes in the brain. In humans, chronic jetlag experienced by airline workers was associated with temporal lobe atrophy (Cho, 2001). The temporal lobe contains the hippocampus and its related cortical structures. As mentioned above, context is thought to be an important component of aggression. Via its connections 
with the OFC and ventral striatum, the hippocampus is involved in contextual representations that influence decision making (Zelinski et al., 2010; Gruber and McDonald, 2012; Trow et al., 2017). The hippocampus has been implicated in aggression, psychopathy, and ASPD with unilateral hippocampal atrophy and hypofunction reported (Raine et al., 1997, 2004; Critchley et al., 2000; Laakso et al., 2000, 2001). In rodents, hippocampal lesions impair the ability to accurately associate a context with an aversive stimulus (contextual fear conditioning; Phillips and LeDoux, 1992; Antoniadis and McDonald, 2000; Sutherland et al., 2010). Interestingly, psychopathy is also associated with impairments in fear conditioning (Flor et al., 2002; Birbaumer et al., 2005).

Structural changes after circadian misalignment have also been documented in animal models. We have found that circadian misalignment induces hippocampal atrophy when paired with a damaging agent (Gidyk et al., 2015). Further structural changes in response to circadian misalignment include changes in neuronal structure and function. In rodents, hippocampal neurogenesis has been shown to be decreased by various light manipulations that induce circadian dysfunction (Gibson et al., 2010; Fujioka et al., 2011). Structurally, dendritic length and density are reduced by circadian disruption in the medial PFC and hippocampus (Bedrosian et al., 2011; Karatsoreos et al., 2011; Fonken et al., 2012).

Second, neuromodulators are also affected by circadian rhythm disruption. Corticosterone, which is the rodent analog of cortisol in humans, can be elevated or phase advanced during circadian rhythm disruption (Gibson et al., 2010; Barclay et al., 2012; Deibel et al., 2014). The relationship between cortisol and testosterone plays a role in aggressive behavior; however, the nature of this relationship varies depending on age, gender, and degree of aggression or psychopathy (Rosell and Siever, 2015). In terms of neurotransmission, Bedrosian and Nelson (2017) suggest that as Maoa expression is oscillatory and regulated by clock genes, it is likely that environmental circadian rhythm disruption affects monoamine neurotransmitters. With this in mind, in rodents, depending on the experimental lighting schedule, 5-HT, DA, and BDNF can all be affected by environmental circadian rhythm disruption paradigms (Shieh et al., 1997; Matsumura et al., 2015; Ikeno and Yan, 2016). As mentioned previously, these neurotransmitter systems are involved in the modulation of aggressive behavior.

Finally, environmental manipulations of the light-dark cycle induce learning and memory impairments in tasks mediated by brain areas and circuits involved in aggression. Shifts of the light-dark cycle or non-24-h days can be used to induce circadian misalignment (Zelinski et al., 2014a; Baron and Reid, 2015). Various paradigms, in rodents, induce memory impairments in tasks that involve the hippocampus, amygdala, medial PFC, and striatum (Devan et al., 2001; Craig and McDonald, 2008; Ruby et al., 2008; Gibson et al., 2010; Loh et al., 2010; McDonald et al., 2013; Zelinski et al., 2013, 2014b; Deibel et al., 2014; Fernandez et al., 2014). Given that circadian rhythm misalignment induces dysfunction in the brain areas and circuits involved in aggression, it is possible that in these models aggression in also elevated. To our knowledge aggression has never been assessed in rodents subjected to environmental circadian rhythm disruption.

Circadian rhythm disruption affects many of the same brain regions, neuromodulators, and circuits that modulate aggressive behavior. It is possible that circadian rhythm disruption is eliciting some of the changes in interactions among learning and memory circuits that we hypothesized contribute to aggression.

\section{SECTION 4: CIRCADIAN MISALIGNMENT AND AGGRESSION}

Hopefully, we have laid out a pathway in which circadian misalignment could affect aggressive behavior by influencing overlapping genetics and neural circuitry. However, the strongest piece of evidence to support this claim would be data that circadian misalignment is associated with increased aggression.

Circadian misalignment is thought to be a mechanism for the effects of chronotype on health and disease; however, as mentioned above, very few studies actually measure circadian misalignment with objective or subjective measures (Baron and Reid, 2015). Also, as the majority of the studies described are correlational, the direction of the true relationship is unknown. It is possible that the behavior or disease state is influencing circadian rhythms (Baron and Reid, 2015; Hood and Amir, 2018). Recently, with the finding that late chronotype is associated with antisocial and borderline personality disorders (Fleischer et al., 2012; Jonason et al., 2013; Schlarb et al., 2014; Rahafar et al., 2017), chronotype has been thought to contribute to aggressive behavior.

While this is a burgeoning area of research, few studies have investigated chronotype and aggression directly. Several studies have investigated chronotype and affective temperaments, which are traits that are thought to predispose one to affective disorders, such as depression and bipolar disorder (Park et al., 2015; Chrobak et al., 2018). Park et al. (2015) found an association between eveningness and traits related to anger, whereas Chrobak et al. (2018) did not detect this association. However, aggression is only indirectly measured in the temperament evaluation of Memphis, Pisa and SanDiego-Autoquestionnaire scale, which was used for both of the aforementioned studies. Some studies have, indeed, measured chronotype and aggression more directly. Readers are encouraged to refer to Schlarb et al. (2014) for a systematic review of chronotype and aggression during childhood and adolescence. Of the 13 studies that met their inclusion criteria, only one did not find a relationship between eveningness and increased aggression (Schlarb et al., 2014). We will focus on several recent studies that have measured chronotype in young adults and adults.

Aspects of reactive aggression has been associated with a late chronotype. Hostility, anger, and impulsivity were increased in those with an evening chronotype (Randler and Vollmer, 2013; Hwang et al., 2016). Interestingly, social jetlag was positively correlated with physical aggression (Randler and Vollmer, 2013). That social jetlag predicted physical 
aggression (Randler and Vollmer, 2013) provides initial evidence that circadian misalignment can elicit aggression. It should be noted however that having a late chronotype does not always infer circadian rhythm disruption. For example, in this study and another that investigated participants with ADHD, social jetlag and chronotype differed in their explanatory power of the dependent variable (Randler and Vollmer, 2013; McGowan et al., 2016).

While factors related to reactive aggression are associated with an evening chronotype, aggression is a very complex behavior that can present in different forms depending on personality traits or psychiatric illness. Some have thought that a subset of humans have evolved to favor more nocturnal activity patterns (Jonason et al., 2013). Nocturnality might be advantageous because less people are active during the night, there is decreased light, and cognition of morning types is compromised (Jonason et al., 2013). It was hypothesized that those with high dark triad personality traits-psychopathy, narcissism, and Machiavellianism-might favor eveningness. Machiavellianism, secondary psychopathy, and exploitive narcissism were correlated with eveningness (Jonason et al., 2013). Secondary psychopathy is characterized by more emotional reactivity and psychological turmoil than primary psychopathy (Vaughn et al., 2009). Except for narcissism, the finding that those scoring higher on the dark triad traits were more prone to eveningness has been replicated (Rahafar et al., 2017). Interestingly, mediation analyses determined that eveningness explained the variance in the effect of gender on the dark triad traits, although this effect was small (Rahafar et al., 2017). These data further confirm that dark triad traits are associated with eveningness and also that eveningness could possibly mediate the tendency for males to score higher in the dark triad traits.

The association of eveningness with increased dark triad traits suggests that factors related to proactive aggression are associated with eveningness. Some recent studies investigate the relationship of chronotype with a new form of proactive aggression. Cyberbullying involves remote digital harassment or mistreatment of people who cannot defend themselves (Içellioğlu and Özden, 2014; Kircaburun and Tosuntaș, 2018; Tosuntaș et al., 2020). Recently, eveningness was found to be associated with the greater commission of cyberbullying by young adults (Kircaburun and Tosuntas, 2018) and adolescents (Tosuntaș et al., 2020). In concert with the dark triad data, the cyberbullying data suggests that proactive aggression is associated with chronotype.

The studies presented in this section demonstrate that factors contributing to both reactive and proactive aggression are associated with an evening preference. It is important to note that these studies measure chronotype primarily with subjective questionnaires. The one study above that used a more quantitative measuring tool (MCTQ) in conjunction with a subjective questionnaire (Randler and Vollmer, 2013), found that the results depended on the tool used. Another caveat to consider is that the majority of the studies that have measured chronotype have sampled the general population. This observation could explain why most studies report relatively small effect sizes (Jonason et al., 2013; Rahafar et al., 2017). To our knowledge, chronotype has not been assessed in people with a protracted history of violence, such as individuals with ASPD or psychopathy. We expect the finding of increased aggression in evening types to be even more pronounced in these individuals. While the evidence suggests that aggression is related to eveningness, the direction and mechanisms for this relationship are unknown. Several studies in this section suggest that circadian misalignment might be a possible mechanism for the relationship between eveningness and increased aggression.

\section{CONCLUSIONS}

With society's reliance on shiftwork and artificial light, it has never been more important to uncover the effects of circadian rhythm disruption on the brain and body. Based on recent behavioral, genetic, and neurobiological research, we suggest that circadian rhythm disruption contributes to aggressive behavior. Behaviorally, recent studies link an evening preference to aggression, and we argue that an evening preference is often associated with mild yet chronic circadian misalignment. Interestingly, genes that are affected by circadian misalignment also contribute to the expression of aggressive behavior. It is possible that circadian misalignment elicited by either genetic variation and/or the environment has a downstream effect on systems that underlie aggression, such as the dopaminergic and serotonergic pathways. In terms of the neurobiology, circadian misalignment induces similar changes in many of the same structures thought to mediate aggression. We hypothesize that changes in the interactions among these circuits are contributing to the manifestation of aggressive behavior. It is important to note that circadian misalignment and aggression is a relatively untouched area of research. It is our hope that the literature reviewed and hypotheses presented in this article serve to spur on future research in this important and topical area of research.

\section{AUTHOR CONTRIBUTIONS}

SD designed the review and wrote the manuscript. RM contributed to the neurobiology section. NK wrote and edited the manuscript.

\section{FUNDING}

This work was supported by a grant from the Canadian Institute of Health Research awarded to NK. SD is supported by a Natural Sciences and Engineering Research Council of Canada (NSERC) postdoctoral fellowship.

\section{ACKNOWLEDGMENTS}

We are grateful to Della Saunders for her help in editing the manuscript. 


\section{REFERENCES}

Adan, A., Archer, S. N., Hidalgo, M. P., Di Milia, L., Natale, V., and Randler, C. (2012). Circadian typology: a comprehensive review. Chronobiol. Int. 29, 1153-1175. doi: 10.3109/07420528.2012.719971

Akram, U., Allen, S., McCarty, K., Gardani, M., Tan, A., Villarreal, D., et al. (2018). The relationship between insomnia symptoms and the dark triad personality traits. Pers. Individ. Dif. 131, 212-215. doi: 10.1016/j.paid.2018.05.001

Alia-Klein, N., Kriplani, A., Pradhan, K., Ma, J. Y., Logan, J., Williams, B., et al. (2008). The MAO-A genotype does not modulate resting brain metabolism in adults. Psychiatry Res. - Neuroimaging 164, 73-76. doi: 10.1016/j.pscychresns. 2007.12.010

Angoa-Pérez, M., Kane, M. J., Briggs, D. I., Sykes, C. E., Shah, M. M., Francescutti, D. M., et al. (2012). Genetic depletion of brain 5HT reveals a common molecular pathway mediating compulsivity and impulsivity. J. Neurochem. 121, 974-984. doi: 10.1111/j.1471-4159.2012.07739.x

Antoniadis, E. A., and McDonald, R. J. (2000). Amygdala, hippocampus and discriminative fear conditioning to context. Behav. Brain Res. 108, 1-19. doi: 10.1016/s0166-4328(99)00121-7

Asher, G., Gatfield, D., Stratmann, M., Reinke, H., Dibner, C., Kreppel, F., et al. (2008). SIRT1 regulates circadian clock gene expression through PER2 deacetylation. Cell 134, 317-328. doi: 10.1016/j.cell.2008.06.050

American Psychiatric Association (2013). Diagnostic and Statistical Manual of Mental Disorders: DSM-5. 5th Edn. Washington, DC: American Psychiatric Association

Baird, A. L., Coogan, A. N., Siddiqui, A., Donev, R. M., and Thome, J. (2012). Adult attention-deficit hyperactivity disorder is associated with alterations in circadian rhythms at the behavioural, endocrine and molecular levels. Mol. Psychiatry 17, 988-995. doi: 10.1038/mp.2011.149

Banks, G., Nolan, P. M., and Peirson, S. N. (2016). Reciprocal interactions between circadian clocks and aging. Mamm. Genome 27, 332-340. doi: 10.1007/s00335016-9639-6

Barclay, N. L., Eley, T. C., Buysse, D. J., Archer, S. N., and Gregory, A. M. (2010). Diurnal preference and slkeep quality: same genes? A study of young adult twins. Chronobiol. Int. 27, 278-296. doi: 10.3109/07420521003 663801

Barclay, N. L., Eley, T. C., Parsons, M. J., Willis, T. A., and Gregory, A. M. (2013). Monozygotic twin differences in non-shared environmental factors associated with chronotype. J. Biol. Rhythms 28, 51-61. doi: 10.1177/07487304124 68698

Barclay, J. L., Husse, J., Bode, B., Naujokat, N., Meyer-Kovac, J., Schmid, S. M., et al. (2012). Circadian desynchrony promotes metabolic disruption in a mouse model of shiftwork. PLoS One 7:e37150. doi: 10.1371/journal.pone.0037150

Barnard, A. R., and Nolan, P. M. (2008). When clocks go bad: neurobehavioural consequences of disrupted circadian timing. PLoS Genet. 4, 1-8. doi: 10.1371/journal.pgen.1000040

Baron, K. G., and Reid, K. J. (2015). Circadian misalignment and health. Int. Rev. Psychiatry 26, 139-154. doi: 10.3109/09540261.2014.911149

Baron, R. A., and Richardson, D. R. (2004). Human Aggression. New York: Springer Science and Business Media.

Bechara, A., Damasio, H., Damasio, A. R., and Lee, G. P. (1999). Different contributions of the human amygdala and ventromedial prefrontal cortex to decision-making. J. Neurosci. 19, 5473-5481. doi: 10.1523/jneurosci.19-1305473.1999

Bedrosian, T. A., Fonken, L. K., Walton, J. C., Haim, A., and Nelson, R. J. (2011). Dim light at night provokes depression-like behaviors and reduces CA1 dendritic spine density in female hamsters. Psychoneuroendocrinology 36, 1062-1069. doi: 10.1016/j.psyneuen.2011.01.004

Bedrosian, T. A., and Nelson, R. J. (2017). Timing of light exposure affects mood and brain circuits. Transl. Psychiatry 7:e1017. doi: 10.1038/tp.2016.262

Bedrosian, T. A., and Nelson, R. J. (2018). "The biology of human aggression," in The Routledge International Handbook of Human Aggression, Current Issues and Perspectives, eds J. L. Ireland, P. Birch, and C. A. Ireland (London: Routledge), 11.

Benus, R. F., Koolhaas, J. M., and Van OOrtmerssen, G. A. (1988). Aggression and adaptation to the light-dark cycle: role of intrinsic and extrinsic control. Physiol. Behav. 43, 131-137. doi: 10.1016/0031-9384(88) 90228-4
Berkowitz, L. (1993). Aggression: Its Causes, Consequences and Control. New York, NY: Mcgraw-Hill Book Company.

Birbaumer, N., Veit, R., Lotze, M., Erb, M., Hermann, C., Grodd, W., et al. (2005). Deficient fear conditioning in psychopathy. Arch. Gen. Psychiatry 62:799. doi: 10.1001/archpsyc.62.7.799

Blair, J. R. (2003). Neurobiological basis of psychopathy. Br. J. Psychiatry 182, 5-7. doi: 10.1192/bjp.182.1.5

Blair, J. R. (2016). The neurobiology of impulsive aggression. J. Child Adolesc. Psychopharmacol. 26, 4-9. doi: 10.1089/cap.2015.0088

Buckholtz, J. W., Treadway, M. T., Cowan, R. L., Woodward, N. D., Benning, S. D., Li, R., et al. (2010). Mesolimbic dopamine reward system hypersensitivity in individuals with psychopathic traits. Nat. Neurosci. 13, 419-421. doi: 10.1038/nn.2510

Burt, S. A. (2009). Are there meaningful etiological differences within antisocial behavior? Results of a meta-analysis. Clin. Psychol. Rev. 29, 163-178. doi: 10.1016/j.cpr.2008.12.004

Buss, A. H., and Durkee, A. (1957). An inventory for assessing different kinds of hostility. J. Consult. Psychol. 21, 343-349. doi: 10.1037/h0046900

Caldwell, H. K., and Albers, H. E. (2004). Effect of photoperiod on vasopressin-induced aggression in Syrian hamsters. Horm. Behav. 46, 444-449. doi: 10.1016/j.yhbeh.2004.04.006

Caspi, A., McClay, J., Moffitt, T. E., Mill, J., Martin, J., Craig, I. W., et al. (2002). Role of genotype in the cycle of violence in maltreated children. Science 297, 851-854. doi: 10.1126/science. 1072290

Chang, H. C., and Guarente, L. (2013). SIRT1 mediates central circadian control in the SCN by a mechanism that decays with aging. Cell 153, 1448-1460. doi: 10.1016/j.cell.2013.05.027

Chang, H. M., Wu, U. I., and Lan, C. T. (2009). Melatonin preserves longevity protein (sirtuin 1) expression in the hippocampus of total sleep-deprived rats. J. Pineal Res. 47, 211-220. doi: 10.1111/j.1600-079x.2009.00704.x

Chang, H. M., Yan, Q., Tang, J., Huang, J., Zhang, Y., Ma, Y., et al. (2017). Possible association between SIRT1 single nucleotide polymorphisms and predisposition to antisocial personality traits in Chinese adolescents. Sci. Rep. 7:1099. doi: 10.1038/s41598-017-01208-2

Cho, K. (2001). Chronic "jet lag" produces temporal lobe atrophy and spatial cognitive deficits. Nat. Neurosci. 4, 567-568. doi: 10.1038/ 88384

Chrobak, A. A., Tereszko, A., Dembinska-Krajewska, D., Arciszewska, A., Dopieraa, E., Siwek, M., et al. (2018). The role of affective temperaments assessed by the temperament evaluation of memphis, pisa and san diegoautoquestionnaire (TEMPS-A) in the relationship between morningnesseveningness and bipolarity. J. Affect. Disord. 232, 83-88. doi: 10.1016/j.jad.2018. 02.017

Chung, S., Lee, E. J., Yun, S., Choe, H. K., Park, S. B., Son, H. J., et al. (2014). Impact of circadian nuclear receptor REV-ERB $\alpha$ on midbrain dopamine production and mood regulation. Cell 157, 858-868. doi: 10.1016/j.cell.2014. 03.039

Coccaro, E. F., Kavoussi, M., Hauger, R. L., Cooper, T. B., and Ferris, C. F. (1998). Cerebrospinal fluid vasopressin levels: correlates with aggression and serotonin function in personality-disordered subjects. Arch. Gen. Psychiatry 55, 708-714. doi: 10.1001/archpsyc.55.8.708

Coid, J., Yang, M., Roberts, A., Ullrich, S., Moran, P., Bebbington, P., et al. (2006). Violence and psychiatric morbidity in the national household population of Britain: public health implications. Br. J. Psychiatry 189, 12-19. doi: 10.1192/bjp.189.1.12

Coogan, A. N., Schutová, B., Husung, S., Furczyk, K., Baune, B. T., Kropp, P., et al. (2013). The circadian system in Alzheimer's disease: disturbances, mechanisms and opportunities. Biol. Psychiatry 74, 333-339. doi: 10.1016/j.biopsych.2012. 11.021

Cope, L. M., Shane, M. S., Segall, J. M., Nyalakanti, P. K., Stevens, M. C., Pearlson, G. D., et al. (2012). Examining the effect of psychopathic traits on gray matter volume in a community substance abuse sample. Psychiatry Res. 204, 1-23. doi: 10.1016/j.pscychresns.2012.10.004

Coque, L., Mukherjee, S., Cao, J. L., Spencer, S., Marvin, M., Falcon, E., et al. (2011). Specific role of VTA dopamine neuronal firing rates and morphology in the reversal of anxiety-related, but not depression-related behavior in the clock $\delta 19$ mouse model of mania. Neuropsychopharmacology 36, 1478-1488. doi: $10.1038 /$ npp. 2011.33 
Craig, L. A., and McDonald, R. J. (2008). Chronic disruption of circadian rhythms impairs hippocampal memory in the rat. Brain Res. Bull. 76, 141-151. doi: 10.1016/j.brainresbull.2008.02.013

Critchley, H. D., Simmons, A., Daly, E. M., Russell, A., van Amelsvoort, T., Robertson, D. M., et al. (2000). Prefrontal and medial temporal correlates of repetitive violence to self and others. Biol. Psychiatry 47, 928-934. doi: 10.1016/s0006-3223(00)00231-6

Crockett, M. J., Apergis-Schoute, A., Herrmann, B., Lieberman, M. D., Müller, U., Robbins, T. W., et al. (2013). Serotonin modulates striatal responses to fairness and retaliation in humans. J. neurosci. 33, 3505-3513. doi: 10.1523/JNEUROSCI.2761-12.2013

da Cunha-Bang, S., McMahon, B., MacDonald Fisher, P., Steen Jensen, P., Svarer, C., and Knudsen, G. M. (2016). High trait aggression in men is associated with low 5-HT levels, as indexed by 5 -HT4receptor binding. Soc. Cogn. Affect. Neurosci. 11, 548-555. doi: 10.1093/scan/nsv140

de Oliveira-Souza, R., Hare, R. D., Bramati, I. E., Garrido, G. J., Ignácio, F. A., Tovar-Moll, F., et al. (2008). Psychopathy as a disorder of the moral brain: fronto-temporo-limbic grey matter reductions demonstrated by voxel-based morphometry. NeuroImage 40, 1202-1213. doi: 10.1016/j.neuroimage.2007. 12.054

Deibel, S. H., Hong, N. S., Himmler, S. M., and McDonald, R. J. (2014). The effects of chronic photoperiod shifting on the physiology of female long-evans rats. Brain Res. Bull. 103, 72-81. doi: 10.1016/j.brainresbull.2014.03.001

Deibel, S. H., and McDonald, R. J. (2017). "The possible role of epigenetics in the memory impairment elicited by circadian rhythm disruption," in Circadian Rhythms and Their Impact on Ageing, eds M. Jazwinski, V. P. Belancio and S. M. Hill (Cham: Springer Science and Business Publishing), 269-304.

Deibel, S. H., Zelinski, E. L., Keeley, R. J., Kovalchuk, O., and McDonald, R. J. (2015). Epigenetic alterations in the suprachiasmatic nucleus and hippocampus contribute to age-related cognitive decline. Oncotarget 6, 23181-23203. doi: 10.18632/oncotarget.4036

Devan, B. D., Goad, E. H., Petri, H. L., Antoniadis, E. A., Hong, N. S., Ko, C. H., et al. (2001). Circadian phase-shifted rats show normal acquisition but impaired long-term retention of place information in the water task. Neurobiol. Learn. Mem. 75, 51-62. doi: 10.1006/nlme.1999.3957

Duffy, J. F., Dijk, D. J., Hall, E. F., and Czeisler, C. A. (1999). Relationship of endogenous circadian melatonin and temperature rhythms to self-reported preference for morning or evening activity in young and older people. J. Investig. Med. 47, 141-150.

Earnest, D. J., Liang, F. Q., Ratcliff, M., and Cassone, V. M. (1999). Immortal time: circadian clock properties of rat suprachiasmatic cell lines. Science 283, 693-695. doi: 10.1126/science.283.5402.693

Ebstein, R. P., Israel, S., Lerer, E., Uzefovsky, F., Shalev, I., Gritsenko, I., et al. (2009). Arginine vasopressin and oxytocin modulate human social behavior. Ann. N. Y. Acad. Sci. 1167, 87-102. doi: 10.1111/j.1749-6632.2009.04541.x

Eckel-Mahan, K. L., and Storm, D. R. (2009). Circadian rhythms and memory: not so simple as cogs and gears. EMBO Rep. 10, 584-591. doi: 10.1038/embor. 2009.123

Ermer, E., Cope, L. M., Calhoun, V. D., Nyalakanti, P. K., and Kiehl, K. A. (2012). Aberrant paralimbic gray matter in criminal psychopathy. 121, 649-658. doi: $10.1037 / \mathrm{a} 0026371$

Escobar, C., Salgado-Delgado, R., Gonzalez-Guerra, E., Tapia Osorio, A., AngelesCastellanos, M., and Buijs, R. M. (2011). Circadian disruption leads to loss of homeostasis and disease. Sleep Disord. 2011:964510. doi: 10.1155/2011/964510

Etcher, L. A., Whall, A., Kumar, R., Devanand, D., and Yeragani, V. (2012). Nonlinear indices of circadian changes in individuals with dementia and aggression. Psychiatry Res. 199, 77-78. doi: 10.1016/j.psychres.2012.03.042

Fang, M., Ohman Strickland, P. A., Kang, H., and Zarbl, H. (2017). Uncoupling genotoxic stress responses from circadian control increases susceptibility to mammary carcinogenesis. Oncotarget 8, 32752-32768. doi: 10.18632/oncotarget.15678

Fazel, S., and Danesh, J. (2002). Serious mental disorder in 23000 prisoners: a systematic review of 62 surveys. Lancet 359, 545-550. doi: 10.1016/s01406736(02)07740-1

Fernandez, F., Lu, D., Ha, P., Costacurta, P., Chavez, R., Heller, H. C., et al. (2014). Dysrhythmia in the suprachiasmatic nucleus inhibits memory processing. Science 346, 854-857. doi: 10.1126/science.1259652
Ferrari, P. F., van Erp, A. M. M., Tornatzky, W., and Miczek, K. A. (2003). Accumbal dopamine and serotonin in anticipation of the next aggressive episode in rats. Eur. J. Neurosci. 17, 371-378. doi: 10.1046/j.1460-9568.2003. 02447.x

Ferris, C. F., Melloni, R. H.Jr., Koppel, G., Perry, K. W., Fuller, R. W., and Delville, Y. (1997). Vasopressin/serotonin interactions in the anterior hypothalamus control aggressive behavior in golden hamsters. J. Neurosci. 17, 4331-4340. doi: 10.1523/jneurosci.17-11-04331.1997

Ferris, C. F., and Potegal, M. (1988). Vasopressin receptor blockade in the anterior hypothalamus suppresses aggression in hamsters. Physiol. Behav. 44, 235-239. doi: 10.1016/0031-9384(88)90144-8

Fleischer, M., Schäfer, M., Coogan, A., Häßler, F., and Thome, J. (2012). Sleep disturbances and circadian CLOCK genes in borderline personality disorder. J. Neural Transm. 119, 1105-1110. doi: 10.1007/s00702-012-0860-5

Flor, H., Birbaumer, N., Hermann, C., Ziegler, S., and Patrick, C. J. (2002). Aversive pavlovian conditioning in psychopaths: peripheral and central correlates. Psychophysiology 39, 505-518. doi: 10.1017.S0048577202394046

Fonken, L. K., Kitsmiller, E., Smale, L., and Nelson, R. J. (2012). Dim nighttime light impairs cognition and provokes depressive-like responses in a diurnal rodent. J. Biol. Rhythms 27, 319-327. doi: 10.1177/0748730412448324

Foster, R. G., Peirson, S. N., Wulff, K., Winnebeck, E., Vetter, C., and Roenneberg, T. (2013). Sleep and circadian rhythm disruption in social jetlag and mental illness. Prog. Mol. Biol. Transl. Sci. 119, 325-346. doi: 10.1016/B9780-12-396971-2.00011-7

Fowler, J. S., Alia-Klein, N., Kriplani, A., Logan, J., Williams, B., Zhu, W., et al. (2007). Evidence that brain MAO a activity does not correspond to MAO A genotype in healthy male subjects. Biol. Psychiatry 62, 355-358. doi: 10.1016/j. biopsych.2006.08.038

Fujioka, A., Fujioka, T., Tsuruta, R., Izumi, T., Kasaoka, S., and Maekawa, T. (2011). Effects of a constant light environment on hippocampal neurogenesis and memory in mice. Neurosci. Lett. 488, 41-44. doi: 10.1016/j.neulet. 2010.11.001

Gao, J., Wang, W.-Y., Mao, Y.-W., Gräff, J., Guan, J.-S., Pan, L., et al. (2010). A novel pathway regulates memory and plasticity via SIRT1 and miR-134. Nature 466, 1105-1109. doi: 10.1038/nature09271

Garaulet, M., Esteban Tardido, A., Lee, Y.-C., Smith, C. E., Parnell, L. D., and Ordovás, J. M. (2012). SIRT1 and CLOCK3111T>C combined genotype is associated with evening preference and weight loss resistance in a behavioral therapy treatment for obesity. Int. J. Obes. 36, 1436-1441. doi: 10.1038/ijo. 2011.270

Gardner, K. J., Archer, J., and Jackson, S. (2012). Does maladaptive coping mediate the relationship between borderline personality traits and reactive and proactive aggression? Aggress. Behav. 38, 403-413. doi: 10.1002/ab. 21437

Giannotti, F., Cortesi, F., Sebastiani, T., and Ottaviano, S. (2002). Circadian preference, sleep and daytime behaviour in adolescence. J. Sleep Res. 11, 191-199. doi: 10.1046/j.1365-2869.2002.00302.x

Gibson, E. M., Wang, C., Tjho, S., Khattar, N., and Kriegsfeld, L. J. (2010). Experimental 'Jet Lag' inhibits adult neurogenesis and produces long-term cognitive deficits in female hamsters. PLoS One 5:e15267. doi: 10.1371/journal. pone.0015267

Gidyk, D. C., Deibel, S. H., Hong, N. S., and McDonald, R. J. (2015). Barriers to developing a valid rodent model of Alzheimer's disease: from behavioural analysis to etiological mechanisms. Front. Neurosci. 9:245. doi: 10.3389/fnins. 2015.00245

Gruber, A. J., and McDonald, R. J. (2012). Context, emotion and the strategic pursuit of goals: interactions among multiple brain systems controlling motivated behavior. Front. Behav. Neurosci. 6:50. doi: 10.3389/fnbeh.2012. 00050

Hampp, G., Ripperger, J. A., Houben, T., Schmutz, I., Blex, C., PerreauLenz, S., et al. (2008). Regulation of monoamine oxidase a by circadianclock components implies clock influence on mood. Curr. Biol. 18, 678-683. doi: 10.1016/j.cub.2008.04.012

Hare, R. D. (1996). Psychopathy a clinical construct whose time has come. Crim. Justice Behav. 23, 25-54.doi: 10.1177/0093854896023001004

Hart, S. D., and Hare, R. D. (1996). Psychopathy and antisocial personality disorder. Curr. Opin. Psychiatry 9, 129-132. 
Haus, E. L., and Smolensky, M. (2006). Biological clocks and shift work: circadian dysregulation and potential long-term effects. Cancer Causes Control 17, 489-500. doi: 10.1007/s10552-005-9015-4

Heyward, F. D., Walton, R. G., Carle, M. S., Coleman, M. A., Garvey, W. T., and Sweatt, J. D. (2012). Adult mice maintained on a high-fat diet exhibit object location memory deficits and reduced hippocampal SIRT1 gene expression. Neurobiol. Learn. Mem. 98, 25-32. doi: 10.1016/j.nlm.2012.04.005

Higley, J. D., Mehlman, P. T., Poland, R. E., Taub, D. M., Wickers, J., Suomi, S. J., et al. (1996). CSF testosterone and 5-HIAA correlate with different types of aggressive behaviors. Biol. Psychiatry 40, 1067-1082. doi: 10.1016/S00063223(95)00675-3

Hood, S., and Amir, S. (2018). Biological clocks and rhythms of anger and aggression. Front. Behav. Neurosci. 12, 1-12. doi: 10.3389/fnbeh.2018.00004

Horne, J. A., and Östberg, O. (1976). A self-assessment questionnaire to determine morningness-eveningness in human circadian rhythms. Int. J. Chronobiol. 4, 97-110.

Horne, C. M., Watts, A. L., and Norbury, R. (2019). The influence of subjective sleep quality on the association between eveningness and depressive symptoms. Biol. Rhythm Res. 50, 534-542. doi: 10.1080/09291016.2018. 1474576

Hu, Y., Shmygelska, A., Tran, D., Eriksson, N., Tung, J. Y., and Hinds, D. A. (2016). GWAS of 89,283 individuals identifies genetic variants associated with self-reporting of being a morning person. Nat. Commun. 7:10448. doi: 10.1038/ncomms10448

Hwang, J. Y., Kang, S. G., Gwak, A. R., Park, J., and Lee, Y. J. (2016). The associations of morningness-eveningness with anger and impulsivity in the general population. Chronobiol. Int. 33, 200-209. doi: 10.3109/07420528.2015. 1128947

İçellioğlu, S., and Özden, M. S. (2014). Cyberbullying: a new kind of peer bullying through online technology and its relationship with aggression and social anxiety. Pro. Soc. Behav. Sci. 116, 4241-4245. doi: 10.1016/j.sbspro.2014.01.924

Ikeno, T., and Yan, L. (2016). Chronic light exposure in the middle of the night disturbs the circadian system and emotional regulation. J. Biol. Rhythms 31, 352-364. doi: 10.1177/0748730416642065

Jonason, P. K., Jones, A., and Lyons, M. (2013). Creatures of the night: chronotypes and the dark triad traits. Pers. Individ. Dif. 55, 538-541. doi: 10.1016/j.paid. 2013.05.001

Jones, S. E., Tyrrell, J., Wood, A. R., Beaumont, R. N., Ruth, K. S., Tuke, M. A., et al. (2016). Genome-wide association analyses in 128,266 individuals identifies new morningness and sleep duration loci. PLoS Genet. 12:e1006125. doi: 10.1371/journal.pgen.1006125

Juda, M., Vetter, C., and Roenneberg, T. (2013). Chronotype modulates sleep duration, sleep quality and social jet lag in shift-workers. J. Biol. Rhythms 28, 141-151. doi: 10.1177/0748730412475042

Kamphuis, J., Meerlo, P., Koolhaas, J. M., and Lancel, M. (2012). Poor sleep as a potential causal factor in aggression and violence. Sleep Med. 13, 327-334. doi: 10.1016/j.sleep.2011.12.006

Karatsoreos, I. N., Bhagat, S., Bloss, E. B., Morrison, J. H., and McEwen, B. S. (2011). Disruption of circadian clocks has ramifications for metabolism, brain and behavior. Proc. Natl. Acad. Sci. U S A 108, 1657-1662. doi: 10.1073/pnas. 1018375108

Katoh-Semba, R., Tsuzuki, M., Miyazaki, N., Matsuda, M., Nakagawa, C., Ichisaka, S., et al. (2008). A phase advance of the light-dark cycle stimulates production of BDNF, but not of other neurotrophins, in the adult rat cerebral cortex: association with the activation of CREB. J. Neurochem. 106, 2131-2142. doi: 10.1111/j.1471-4159.2008.05565.x

Katz, G., Durst, R., Zislin, Y., Barel, Y., and Knobler, H. Y. (2001). Psychiatric aspects of jet lag: review and hypothesis. Med. Hypotheses 56, 20-23. doi: 10.1054/mehy.2000.1094

Katzenberg, D., Young, T., Finn, L., King, D., and Takahashi, J. (1998). A CLOCK polymorphism associated with human diurnal preference. Sleep 1, 569-576. doi: 10.1093/sleep/21.6.569

Kendler, K. S., Aggen, S. H., Knudsen, G. P., Roysamb, E., Neale, M. C., and Reichborn-Kjennerud, T. (2011). The structure of genetic and environmental risk factors for syndromal and subsyndromal common DSM-IV axis I and all axis II disorders. Am. J. Psychiatry 168, 29-39. doi: 10.1176/appi.ajp.2010. 10030340
Kerkhof, G. A., and Lancel, M. (1991). EEG slow wave activity, REM sleep and rectal temperature during night and day sleep in morning-type and eveningtype subjects. Psychophysiology 28, 678-688. doi: 10.1111/j.1469-8986.1991. tb01014.x

Kerman, I. A., Clinton, S. M., Simpson, D. N., Bedrosian, B. S., Bernard, R., Akil, H., et al. (2012). Inborn differences in environmental reactivity predict divergent diurnal behavioral, endocrine and gene expression rhythms. Psychoneuroendocrinology 37, 256-269. doi: 10.1016/j.psyneuen.2011.06.010

Kircaburun, K., and Tosuntaș, S,. B. (2018). Cyberbullying perpetration among undergraduates: evidence of the roles of chronotype and sleep quality. Biol. Rhythm Res. 49, 247-265. doi: 10.1080/02723646.2017.1352918

Kockler, T. R., Stanford, M. S., Nelson, C. E., Meloy, J. R., and Sanford, K. (2006). Characterizing aggressive behavior in a forensic population. Am. J. Orthopsychiatry 76:80. doi: 10.1037/0002-9432.76.1.80

Kolla, N. J., Dunlop, K., Downar, J., Links, P., Michael Bagby, R., Wilson, A. A., et al. (2016). Association of ventral striatum monoamine oxidase-A binding and functional connectivity in antisocial personality disorder with high impulsivity: a positron emission tomography and functional magnetic resonance imaging study. Eur. Neuropsychopharmacol. 26, 777-786. doi: 10.1016/j.euroneuro.2015.12.030

Kolla, N. J., Dunlop, K., Meyer, J. H., and Downar, J. (2018). Corticostriatal connectivity in antisocial personality disorder by MAO-A genotype and its relationship to aggressive behavior. Int. J. Neuropsychopharmacol. 21, 725-733. doi: 10.1093/ijnp/pyy035

Kolla, N. J., Gregory, S., Attard, S., Blackwood, N., and Hodgins, S. (2014). Disentangling possible effects of childhood physical abuse on gray matter changes in violent offenders with psychopathy. Psychiatry Res. 221, 123-126. doi: 10.1016/j.pscychresns.2013.11.008

Kolla, N. J., Meyer, J., Sanches, M., and Charbonneau, J. (2017a). Monoamine Oxidase-A genetic variants and childhood abuse predict impulsiveness in borderline personality disorder. Clin. Psychopharmacol. Neurosci. 15, 343-351. doi: 10.9758/cpn.2017.15.4.343

Kolla, N. J., Patel, R., Meyer, J. H., and Chakravarty, M. M. (2017b). Association of monoamine oxidase-A genetic variants and amygdala morphology in violent offenders with antisocial personality disorder and high psychopathic traits. Sci. Rep. 7:9607. doi: 10.1038/s41598-017-08351-w

Kolla, N. J., and Vinette, S. A. (2017). Monoamine oxidase a in antisocial personality disorder and borderline personality disorder. Curr. Behav. Neurosci. Rep. 4, 41-48. doi: 10.1007/s40473-017-0102-0

Koenigs, M., Young, L., Adolphs, R., Tranel, D., Cushman, F., Hauser, M., et al. (2007). Damage to the prefrontal cortex increases ultilitarian moral judgements. Nature 446, 908-911. doi: 10.1038/nature05631

Korponay, C., Pujara, M., Deming, P., Philippi, C., Decety, J., Kosson, D. S., et al. (2017). Impulsive-antisocial dimension of psychopathy linked to enlargment and abnormal functional connectivity of the striatum. Biol. Psychiatry Cogn. Neurosci. Neuroimaging 2, 149-157. doi: 10.1016/j.bpsc.2016.07.004

Koskenvuo, M., Hublin, C., Partinen, M., Heikkilä, K., and Kaprio, J. (2007). Heritability of diurnal type: a nationwide study of 8753 adult twin pairs. J. Sleep Res. 16, 156-162. doi: 10.1111/j.1365-2869. 2007.00580.x

Kretschmer, T., Vitaro, F., and Barker, E. D. (2012). The association between peer and own aggression is moderated by the BDNF val-met polymorphism. J. Res. Adolesc. 40, 1301-1315. doi: 10.1111/jora.12050

Kripke, D. F., Rex, K. M., Ancoli-Israel, S., Nievergelt, C. M., Klimecki, W., and Kelsoe, J. R. (2008). Delayed sleep phase cases and controls. J. Circadian Rhythms 6:6. doi: 10.1186/1740-3391-6-6

Krishnan, H. C., and Lyons, L. C. (2015). Synchrony and desynchrony in circadian clocks: impacts on learning and memory. Learn. Mem. 22, 426-437. doi: 10.1101/lm.038877.115

Krizan, Z., and Herlache, A. D. (2016). Sleep disruption and aggression: implications for violence and its prevention. Psychol. Viol. 6, 542-552. doi: $10.1037 /$ vio0000018

Kuhn, G. (2001). Circadian rhythm, shift work and emergency medicine. Ann. Emerg. Med. 37, 88-98. doi: 10.1067/mem.2001.111571

Laakso, M. P., Vaurio, O., Koivisto, E., and Savolainen, L. (2001). Psychopathy and the posterior hippocampus. Behav. Brain Res. 118, 187-193. doi: $10.1016 /$ s0166-4328(00)00324-7 
Laakso, M. P., Vaurio, O., Savolainen, L., Repo, E., Soininen, H., Aronen, H. J., et al. (2000). A volumetric MRI study of the hippocampus in type 1 and 2 alcoholism. Behav. Brain Res. 109, 177-186. doi: 10.1016/s0166-4328(99)00172-2

Levandovski, R., Sasso, E., and Hidalgo, M. P. (2013). Chronotype: a review of the advances, limits and applicability of the main instruments used in the literature to assess human phenotype. Trends Psychiatry Psychother. 35, 3-11. doi: 10.1590/s2237-60892013000100002

Liang, F. Q., Allen, G., and Earnest, D. (2000). Role of brain-derived neurotrophic factor in the circadian regulation of the suprachiasmatic pacemaker by light. J. Neurosci. 20, 2978-2987. doi: 10.1523/jneurosci.20-08-02978.2000

Liang, F. Q., Walline, R., and Earnest, D. J. (1998). Circadian rhythm of brainderived neurotrophic factor in the rat suprachiasmatic nucleus. Neurosci. Lett. 242, 89-92. doi: 10.1016/s0304-3940(98)00062-7

Libert, S., Pointer, K., Bell, E. L., Das, A., Cohen, D. E., Asara, J. M., et al. (2011). SIRT1 activates MAO-A in the brain to mediate anxiety and exploratory drive. Cell 147, 1459-1472. doi: 10.1016/j.cell.2011.10.054

Ling, S., and Raine, A. (2018). The neuroscience of psychopathy and forensic implications. Psychol. Crime Law 24, 296-312. doi: 10.1080/1068316x.2017. 1419243

Lobbestael, J., Cima, M., and Arntz, A. (2013). The relationship between adult reactive and proactive aggression, hostile interpretation bias and antisocial personality disorder. J. Pers. Disord. 27, 53-66. doi: 10.1521/pedi.2013.27.1.53

Logan, R. W., Parekh, P. K., Kaplan, G. N., Becker-Krail, D. D., Williams, W. P., Yamaguchi, S., et al. (2018). NAD+ cellular redox and SIRT1 regulate the diurnal rhythms of tyrosine hydroxylase and conditioned cocaine reward. Mol. Psychiatry 24, 1-17. doi: 10.1038/s41380-018-0061-1

Loh, D. H., Navarro, J., Hagopian, A., Wang, L. M., Deboer, T., and Colwell, C. S. (2010). Rapid changes in the light/dark cycle disrupt memory of conditioned fear in mice. PLoS One 5:e12546. doi: 10.1371/journal.pone.0012546

Matsumura, T., Nakagawa, H., Suzuki, K., Ninomiya, C., and Ishiwata, T. (2015). Influence of circadian disruption on neurotransmitter levels, physiological indexes and behaviour in rats. Chronobiol. Int. 32, 1449-1457. doi: 10.3109/07420528.2015.1105250

Matthies, S., Rüsch, N., Weber, M., Lieb, K., Philipsen, A., Tuescher, O., et al. (2012). Small amygdala - high aggression? The role of the amygdala in modulating aggression in healthy subjects. World Biol. Psychiatry 13, 75-81. doi: $10.3109 / 15622975.2010 .541282$

McDonald, R. J., Devan, B. D., and Hong, N. S. (2004). Multiple memory systems: the power of interactions. Neurobiol. Learn. Mem. 82, 333-346. doi: 10.1016/j. nlm.2004.05.009

McDonald, R. J., Hong, N. S., and Devan, B. D. (2017). "Interactions among multiple parallel learning and memory systems in the mammalian brain," in Reference Module in Neuroscience and Biobehavioral Psychology, eds J. H. Byrne, and H. Eichenbaum (Oxford: Academic Press), 1-33.

McDonald, R. J., Zelinski, E. L., Keeley, R. J., Sutherland, D., Fehr, L., and Hong, N. S. (2013). Multiple effects of circadian dysfunction induced by photoperiod shifts: alterations in context memory and food metabolism in the same subjects. Physiol. Behav. 118, 14-24. doi: 10.1016/j.physbeh.2013.04.010

McGowan, N. M., Voinescu, B. I., and Coogan, A. N. (2016). Sleep quality, chronotype and social jetlag differentially associate with symptoms of attention deficit hyperactivity disorder in adults. Chronobiol. Int. 33, 1433-1443. doi: 10.1080/07420528.2016.1208214

Meijers, J., Harte, J. M., and Scherder, F. V. (2015). Disturbed sleep as a risk factor for aggression in prisoners with a psychotic illness: a brief report. Psychol. Crime Law 21, 968-972. doi: 10.1080/1068316x.2015.1077246

Merrow, M., Spoelstra, K., and Roenneberg, T. (2005). The circadian cycle: daily rhythms from behaviour to genes. EMBO Rep. 6, 930-935. doi: 10.1038/sj. embor.7400541

Michel, S., Clark, J. P., Ding, J. M., and Colwell, C. S. (2006). Brain-derived neurotrophic factor and neurotrophin receptors modulate glutamate-induced phase shifts of the suprachiasmatic nucleus. Eur. J. Neurosci. 24, 1109-1116. doi: 10.1111/j.1460-9568.2006.04972.x

Mogavero, F., Jager, A., and Glennon, J. C. (2018). Clock genes, ADHD and aggression. Neurosci. Biobehav. Rev. 91, 51-68. doi: 10.1016/j.neubiorev.2016. 11.002

Mongrain, V., Carrier, J., and Dumont, M. (2006). Circadian and homeostatic sleep regulation in morningness eveningness. J. Sleep Res. 15, 162-166. doi: $10.1111 /$ j.1365-2869.2006.00532.x
Naert, G., Ixart, G., Tapia-Arancibia, L., and Givalois, L. (2006). Continuous i.c.v. infusion of brain-derived neurotrophic factor modifies hypothalamicpituitary-adrenal axis activity, locomotor activity and body temperature rhythms in adult male rats. Neuroscience 139, 779-789. doi: 10.1016/j. neuroscience.2005.12.028

Nakahata, Y., Kaluzova, M., Grimaldi, B., Sahar, S., Hirayama, J., Chen, D., et al. (2008). The NAD+-dependent deacetylase SIRT1 modulates CLOCK-mediated chromatin remodeling and circadian control. Cell 134, 329-340. doi: 10.1016/j. cell.2008.07.002

Nakahata, Y., Sahar, S., Astarita, G., Kaluzova, M., and Sassone-Corsi, P. (2009). Circadian control of the NAD+ salvage pathway by CLOCK-SIRT1. Science 324, 654-657. doi: 10.1126/science. 1170803

Naumenko, V. S., Kondaurova, E. M., Bzovkina, D. V., Tsybko, A. S., Ill'chibaeva, T. V., and Popova, N. K. (2014). On the role of 5-HT1A receptor gene in behavioral effect of brain-derived neurotrophic factor. J. Neurosci. Res. 92, 1035-1043. doi: 10.1002/jnr.23381

Navara, K. J., and Nelson, R. J. (2007). The dark side of light at night: physiological, epidemiological and ecological consequences. J. Pineal Res. 43, 215-224. doi: 10.1111/j.1600-079x.2007.00473.x

Okamura, H. (2004). Clock genes in cell clocks: roles, actions and mysteries. J. Biol. Chem. 19, 388-399. doi: 10.1177/0748730404269169

Pappa, I., St Pourcain, B., Benke, K., Cavadino, A., Hakulinen, C., Nivard, M. G., et al. (2016). A genome-wide approach to children's aggressive behavior: the EAGLE consortium. Am. J. Med. Genet. B Neuropsychiatr. Genet. 171, 562-572. doi: 10.1002/ajmg.b.32333

Pardini, D. A., Raine, A., Erickson, K., and Loeber, R. (2014). Lower amygdala volume in men is associated with childhood aggresssion, early psychopathic traits and future violence. Biol. Psychiatry 75, 1-23. doi: 10.1016/j.biopsych. 2013.04.003

Park, C. I., An, S. K., Kim, H. W., Koh, M. J., Namkoong, K., Kang, J. I., et al. (2015). Relationships between chronotypes and affective temperaments in healthy young adults. J. Affect. Disord. 175, 256-259. doi: 10.1016/j.jad.2015. 01.004

Peixoto, L. L., Wimmer, M. E., Poplawski, S. G., Tudor, J. C., Kenworthy, C. A., Liu, S., et al. (2015). Memory acquisition and retrieval impact different epigenetic processes that regulate gene expression. BMC Genomics 16:S5. doi: 10.1186/1471-2164-16-s5-s5

Phillips, R. G., and LeDoux, J. E. (1992). Differential contribution of amygdala and hippocampus and its connection to activity in other brain structures. Behav. Neurosci. 106, 274-285. doi: 10.1037//0735-7044.106.2.274

Provençal, N., Booij, L., and Tremblay, R. E. (2015). The developmental origins of chronic physical aggression: biological pathways triggered by early life adversity. J. Exp. Biol. 218, 123-133. doi: 10.1242/jeb. 111401

Provençal, N., Suderman, M. J., Guillemin, C., Vitaro, F., Côté, S. M., Hallett, M., et al. (2014). Association of childhood chronic physical aggression with a DNA methylation signature in adult human T cells. PLoS One 9:e89839. doi: 10.1371/journal.pone.0089839

Rahafar, A., Randler, C., Castellana, I., and Kausch, I. (2017). How does chronotype mediate gender effect on dark triad? Pers. Individ. Dif. 108, 35-39. doi: $10.1016 /$ j.paid.2016.12.002

Raine, A., Buchsbaum, M., and LaCasse, L. (1997). Brain abnormalities in murderers indicated by positron emission tomography. Biol. Psychiatry 42, 495-508. doi: 10.1016/S0006-3223(96)00362-9

Raine, A., Dodge, K., Loeber, R., Gatzke-Kopp, L., Lynam, D., Reynolds, C., et al. (2006). The reactive-proactive aggression questionnaire: differential correlates of reactive and proactive aggression in adolescent boys. Aggress. Behav. 32, 159-171. doi: 10.1002/ab.20115

Raine, A., Ishikawa, S. S., Arce, E., Lencz, T., Knuth, K. H., Bihrle, S., et al. (2004). Hippocampal structural asymmetry in unsuccessful psychopaths. Biol. Psychiatry 55, 185-191. doi: 10.1016/s0006-3223(03)00727-3

Ralph, M. R., Sam, K., Rawashdeh, O. A., Cain, S. W., and Ko, C. H. (2013). Memory for time of day (time memory) is encoded by a circadian oscillator and is distinct from other context memories. Chronobiol. Int. 30, 540-547. doi: 10.3109/07420528.2012.754449

Ramboz, S., Saudou, F., Amara, D. A., Belzung, C., Segu, L., Misslin, R., et al. (1995). 5-HT1B receptor knock out-behavioral consequences. Behav. brain Res. 73, 305-312. doi: 10.1016/0166-4328(96)00119-2 
Randler, C., Schredl, M., and Göritz, A. S. (2017). Chronotype, sleep behavior and the big five personality factors. SAGE Open 7:215824401772832. doi: $10.1177 / 2158244017728321$

Randler, C., and Vollmer, C. (2013). Aggression in young adults-a matter of short sleep and social jetlag? Psychol. Rep. 113, 754-765. doi: 10.2466/16.02. PR0.113x31z7

Rawashdeh, O., Jilg, A., Jedlicka, P., Slawska, J., Thomas, L., Saade, A., et al. (2014). PERIOD1 coordinates hippocampal rhythms and memory processing with daytime. Hippocampus 24, 712-723. doi: 10.1002/hipo.22262

Reef, J., Diamantopoulou, S., Van Meurs, I., Verhulst, F. C., and Van Der Ende, J. (2011). Developmental trajectories of child to adolescent externalizing behavior and adult DSM-IV disorder: results of a 24-year longitudinal study. Soc. Psychiatry Psychiatr. Epidemiol. 46, 1233-1241. doi: 10.1007/s00127-0100297-9

Reinberg, A., and Ashkenazi, I. (2008). Internal desynchronization of circadian rhythms and tolerance to shift work. Chronobiol. Int. 25, 625-643. doi: 10.1080/07420520802256101

Reppert, S. M., and Weaver, D. R. (2001). Molecular analysis of mammalian circadian rhythms. Annu. Rev. Physiol. 63, 647-676. doi: 10.1146/annurev. physiol.63.1.647

Robilliard, D. L., Archer, S. N., Arendt, J., Lockley, S. W., Hack, L. M., English, J., et al. (2002). The 3111 clock gene polymorphism is not associated with sleep and circadian rhythmicity in phenotypically characterized human subjects. J. Sleep Res. 11, 305-312. doi: 10.1046/j.1365-2869.2002.00320.x

Roenneberg, T. (2012). What is chronotype? Sleep Biol. Rhythms 10, 75-76. doi: 10.1111/j.1479-8425.2012.00541.x

Roenneberg, T., Allebrandt, K. V., Merrow, M., and Vetter, C. (2012). Social jetlag and obesity. Curr. Biol. 22, 939-943. doi: 10.1016/j.cub.2012.03.038

Roenneberg, T., Kuehnle, T., Pramstaller, P. P., Ricken, J., Havel, M., Guth, A., et al. (2004). A marker for the end of adolescence. Curr. Biol. 14, 1038-1039. doi: $10.1016 /$ j.cub.2004.11.039

Roenneberg, T., and Merrow, M. (2016). The circadian clock and human health. Curr. Biol. 26, R432-R443. doi: 10.1016/j.cub.2016.04.011

Roenneberg, T., Wirz-Justice, A., and Merrow, M. (2003). Life between clocks: daily temporal patterns of human chronotypes. J. Biol. Rhythms 18, 80-90. doi: 10.1177/0748730402239679

Rosell, D. R., and Siever, L. J. (2015). The neurobiology of aggression and violence. CNS Spectr. 20, 254-279. doi: 10.1017/S109285291500019X

Roybal, K., Theobold, D., Graham, A., DiNieri, J. A., Russo, S. J., Krishnan, V., et al. (2007). Mania-like behavior induced by disruption of CLOCK. Proc. Natl. Acad. Sci. U S A 104, 6406-6411. doi: 10.1073/pnas.0609625104

Ruby, N. F., Hwang, C. E., Wessells, C., Fernandez, F., Zhang, P., Sapolsky, R., et al. (2008). Hippocampal-dependent learning requires a functional circadian system. Proc. Natl. Acad. Sci. U S A 105, 15593-15598. doi: 10.1073/pnas. 0808259105

Rudenko, A., and Tsai, L.-H. (2014). Epigenetic regulation in memory and cognitive disorders. Neuroscience 264, 51-63. doi: 10.1016/j.neuroscience.2012. 12.034

Sabouri, S., Gerber, M., Lemola, S., Becker, S. P., Shamsi, M., Shakouri, Z., et al. (2016). Examining dark triad traits in relation to sleep disturbances, anxiety sensitivity and intolerance of uncertainty in young adults. Compr. Psychiatry 68, 103-110. doi: 10.1016/j.comppsych.2016.03.012

Saksvik-Lehouillier, I., Pallesen, S., Bjorvatn, B., Mageroy, N., and Folkard, S. (2015). Towards a more comprehensive definition of shift work tolerance. Ind. Health 53, 69-77. doi: 10.2486/indhealth.2014-0112

Schaaf, M. J., Duurland, R., de Kloet, E. R., and Vreugdenhil, E. (2000). Circadian variation in BDNF mRNA expression in the rat hippocampus. Brain Res. Mol. Brain Res. 75, 342-344. doi: 10.1016/s0169-328x(99)00314-9

Schlarb, A. A., Sopp, R., Ambiel, D., and Grünwald, J. (2014). Chronotype-related differences in childhood and adolescent aggression and antisocial behavior-a review of the literature. Chronobiol. Int. 31, 1-16. doi: 10.3109/07420528.2013. 829846

Schlüter, T., Winz, O., Henkel, K., Prinz, S., Rademacher, L., Schmaljohann, J., et al. (2013). The impact of dopamine on aggression: an $\left[{ }^{18} \mathrm{~F}\right]$-FDOPA PET study in healthy males. J. Neurosci. 33, 16889-16896. doi: 10.1523/jneurosci. 1398-13.2013

Sei, H., Fujihara, H., Ueta, Y., Morita, K., Kitahama, K., and Morita, Y. (2003). Single eight-hour shift of light-dark cycle increases brain-derived neurotrophic factor protein levels in the rat hippocampus. Life Sci. 73, 53-59. doi: 10.1016/s0024-3205(03)00251-0

Shieh, K. R., Chu, Y. S., and Pan, J. T. (1997). Circadian change of dopaminergic neuron activity: effects of constant light and melatonin. Neuroreport 8, 2283-2287. doi: 10.1097/00001756-199707070-00037

Shumay, E., Logan, J., Volkow, N. D., and Fowler, J. S. (2012). Evidence that the methylation state of the monoamine oxidase A (MAOA) gene predicts brain activity of MAOA enzyme in healthy men. Epigenetics 7, 1151-1160. doi: $10.4161 /$ epi.21976

Song, Z., and Albers, H. E. (2018). Cross-talk among oxytocin and argininevasopressin receptors: relevance for basic and clinical studies of the brain and periphery. Front. Neuroendocrinol. 51, 14-24. doi: 10.1016/j.yfrne.2017.10.004

Stanford, M. S., Houston, R. J., and Baldridge, R. M. (2008). Comparison of impulsive and premeditated perpetrators of intimate partner violence. Behav. Sci. Law 26, 709-722. doi: 10.1002/bsl.808

Sutherland, R. J., Sparks, F. T., and Lehmann, H. (2010). Hippocampus and retrograde amnesia in the rat model: a modest proposal for the situation of systems consolidation. Neuropsychol. 48, 2357-2369. doi: 10.1016/ j.neuropsychologia.2010.04.015

Swanson, M., Bland, R., and Newman, S. (1994). Antisocial personality disorders. Acta Psychiatr. Scand. 89, 63-70.

Swogger, M. T., Walsh, Z., Christie, M., Priddy, B. M., and Conner, K. R. (2015). Impulsive versus premediatated aggression in the prediction of violent criminal recidivism. Aggress. Behav. 41, 346-352. doi: 10.1002/ab.21549

Taillard, J., Philip, P., Chastang, J. F., and Bioulac, B. (2004). Validation of horne and ostberg morningness-eveningness questionnaire in a middle-aged population of french workers. J. Biol. Rhythms 19, 76-86. doi: $10.1177 / 0748730403259849$

Taillard, J., Philip, P., Coste, O., Sagaspe, P., and Bioulac, B. (2003). The circadian and homeostatic modulation of sleep pressure during wakefulness differs between morning and evening chronotypes. J. Sleep Res. 12, 275-282. doi: 10.1046/j.0962-1105.2003.00369.x

Takahashi, J. (2017). Transcriptional architecture of the mammalian circadian clock. Nat. Rev. Genet. 18, 164-179. doi: 10.1038/nrg.2016.150

Temcheff, C. E., Serbin, L. A., Martin-Storey, A., Stack, D. M., Hastings, P., Ledingham, J., et al. (2011). Childhood aggression, withdrawal and likeability and the use of health care later: a longitudinal study. CMAJ 183, 2095-2101. doi: 10.1503/cmaj.091830

Tiihonen, J., Rautiainen, M., Ollila, H., Repo-Tiihonen, E., Virkkunen, M., Palotie, A., et al. (2015). Genetic background of extreme violent behavior. Mol. Psychiatry 20, 786-792. doi: 10.1038/mp.2014.130

Todd, W. D., Fenselau, H., Wang, J. L., Zhang, R., Machado, N. L., Venner, A., et al. (2018). A hypothalamic circuit for the circadian control of aggression. Nat. Neurosci. 21, 717-724. doi: 10.1038/s41593-018-0126-0

Tosuntaş, Ș. B., Balta, S., Emirtekin, E., Kircaburun, K., and Griffiths, M. D. (2020). Adolescents' eveningness chronotype and cyberbullying perpetration: the mediating role of depression-related aggression and anxiety-related aggression. Biol. Rhythm Res. 51, 40-50. doi: 10.1080/09291016.2018.1513132

Trow, J. E., Hong, N. S., Jones, A. M., Lapointe, J., MacPhail, J. K., and McDonald, R. J. (2017). Evidence of a role for orbital prefrontal cortex in preventing over-generalization to moderate predictors of biologically significant events. Neuroscience 345, 49-63. doi: 10.1016/j.neuroscience.2016. 10.017

Tuinier, S., Verhoeven, W. M. A., and Van Praag, H. M. (1995). Cerebrospinal fluid 5-hydroxyindolacetic acid and aggression: a critical reappraisal of the clinical data. Psychopharmacology 10, 147-156. doi: 10.1097/00004850199510030-00003

Tuvblad, C., and Baker, L. A. (2011). Human aggression across the lifespan: genetic propensities and environmental moderators. Adv. Genet. 75, 171-214. doi: 10.1016/B978-0-12-380858-5.00007-1

van Donkelaar, M. M. J. (2018). Genetic and neurobiological mechanisms underlying aggression subtypes (Doctoral dissertation, [Sl: sn]).

van Donkelaar, M. M. J., Hoogman, M., Shumskaya, E., Buitelaar, J. K., Bralten, J., and Franke, B. (2020). Monoamine and neuroendocrine gene-sets associate with frustration-based aggression in a gender-specific manner. Eur. Neuropsychopharmacol. 30, 75-86. doi: 10.1016/j.euroneuro.2017.11.016

Vaughn, M. G., Edens, J. F., Howard, M. O., and Smith, S. T. (2009). An investigation of primary and secondary psychopathy in a statewide 
sample of incarcerated youth. Youth Violence Juv. Justice 7, 172-188. doi: $10.1177 / 1541204009333792$

Veroude, K., Zhang-James, Y., Fernàndez-Castillo, N., Bakker, M. J., Cormand, B., and Faraone, S. V. (2016). Genetics of aggressive behavior: an overview. Am. J. Med. Genet. B Neuropsychiatr. Genet. 171, 3-43. doi: 10.1002/ajmg.b.32364

Vogler, N., Perkinson-Gloor, N., Brand, S., Grob, A., and Lemola, S. (2014). Sleep, aggression and psychosocial adjustment in male prisoners. Swiss J. Psychol. 73, 167-176. doi: 10.1024/1421-0185/a000137

Wagner, S., Baskaya, Ö., Dahmen, N., Lieb, K., and Tadić, A. (2010). Modulatory role of the brain-derived neurotrophic factor $\mathrm{Val}^{66} \mathrm{Met}$ polymorphism on the effects of serious life events on impulsive aggression in borderline personality disorder. Genes Brain Behav. 9, 97-102. doi: 10.1111/j.1601-183x.2009.00539.x

Waltes, R., Chiocchetti, A. G., and Freitag, C. M. (2016). The neurobiological basis of human aggression: a review on genetic and epigenetic mechanisms. Am. J. Med. Genet. Part B Neuropsychiatr. Genet. 171, 650-675. doi: 10.1002/ajmg. b. 32388

Walters, G. D., and Ruscio, J. (2013). Trajectories of youthful antisocial behavior: categories or continua?. J. Abnorm. Child Psychol. 41, 653-666. doi: 10.1007/s10802-012-9700-1

Wicht, H., Korf, H.-W., Ackermann, H., Ekhart, D., Fischer, C., and Pfeffer, M. (2014). Chronotypes and rhythm stability in mice. Chronobiol. Int. 31, 27-36. doi: 10.3109/07420528.2013.820739

Wistedt, B., Rasmussen, A., Pedersen, L., Malm, U., Träskman-Bendz, L., Wakelin, J., et al. (1990). The development of an observer-scale for measuring social dysfunction and aggression. Pharmacopsychiatry 23, 249-252. doi: 10.1055/s-2007-1014514

Wittmann, M., Dinich, J., Merrow, M., and Roenneberg, T. (2006). Social jetlag: misalignment of biological and social time. Chronobiol. Int. 23, 497-509. doi: 10.1080/07420520500545979

Wrangham, R. W. (2018). Two types of aggression in human evolution. Proc. Natl. Acad. Sci. U S A 115, 245-253. doi: 10.1073/pnas.1713611115
Yamaguchi, Y., Suzuki, T., Mizoro, Y., Kori, H., Okada, K., Chen, Y., et al. (2013). Mice genetically deficient in vasopressin V1a and V1b receptors are resistant to jet lag. Science 342, 85-90. doi: 10.1126/science. 1238599

Zelinski, E. L., Deibel, S. H., and McDonald, R. J. (2014a). The trouble with circadian clock dysfunction: multiple deleterious effects on the brain and body. Neurosci. Biobehav. Rev. 40, 80-101. doi: 10.1016/j.neubiorev.2014. 01.007

Zelinski, E. L., Hong, N. S., and McDonald, R. J. (2014b). Persistent impairments in hippocampal function following a brief series of photoperiod shifts in rats. Anim. Cogn. 17, 127-141. doi: 10.1007/s10071-013-0645-8

Zelinski, E. L., Hong, N. S., Tyndall, A. V., Halsall, B., and McDonald, R. J. (2010). Prefrontal cortical contributions during discriminative fear conditioning, extinction and spontaneous recovery in rats. Exp. Brain Res. 203, 285-297. doi: 10.1007/s00221-010-2228-0

Zelinski, E. L., Tyndall, A. V., Hong, N. S., and McDonald, R. J. (2013). Persistent impairments in hippocampal, dorsal striatal and prefrontal cortical function following repeated photoperiod shifts in rats. Exp. Brain Res. 224, 125-139. doi: 10.1007/s00221-012-3293-3

Conflict of Interest: The authors declare that the research was conducted in the absence of any commercial or financial relationships that could be construed as a potential conflict of interest.

Copyright (c) 2020 Deibel, McDonald and Kolla. This is an open-access article distributed under the terms of the Creative Commons Attribution License (CC BY). The use, distribution or reproduction in other forums is permitted, provided the original author(s) and the copyright owner(s) are credited and that the original publication in this journal is cited, in accordance with accepted academic practice. No use, distribution or reproduction is permitted which does not comply with these terms. 